\title{
THE GROWTH OF ORGANS IN THE ALBINO RAT AS AFFECTED BY GONADECTOMY
}

\author{
SHINKISHI HATAI
}

The Wistar Institute of Anatomy and Biology

The object of the present paper is twofold. (1) To test the several findings given in my previous work on the effect of gonadectomy (Hatai '13) and (2) to extend similar observations to several other ductless glands besides the hypophysis and ovaries. Furthermore, the present paper includes observations on the effect of semi-castration, ligation of the spermatic cords, and isolation of the ovaries from the uterus. In some series the weight and length of various bones, as well as the weights of parts of the encephalon, have been investigated also.

For this discussion $I$ have found it convenient to introduce the word 'gonadectomy;' a word proposed to cover both castration and spaying. As the literature shows, the word 'castration' is often used for operations on both males and females, while in some instances castration is applied only to operations on the males; and for those on the female the word 'ovariotomy' or 'spaying' is used. This double use of the word 'castration,' signifying either the removal of the testes alone, or the sex glands of both sexes, makes for confusion.

The term 'gonadectomy' is useful therefore not only because it reduces to one word the expression "removal of the sex glands in either sex" but also because it leaves 'castration' to apply to the operation on the male, while that on the female is designated by 'spaying.' In this paper, therefore, the word gonadectomy is used throughout, whenever reference is made to the removal of the sex glands in both sexes, or without distinction of sex. 


\section{MATERIAL}

The albino rats which have been used were obtained from the colony at The Wistar Institute during 1912 to 1913 . The individuals belonging to the same litter were divided into two lots; one lot for control and the other for operation. The comparison is thus made always within the litter. This method of comparison is the best, since as shown by Jackson ('13) the variability of the body weight in the litter is only about one half that in the total population. It is further the impression of the present writer that peculiarities, when present, are usually found in most of the members of the same litter.

In the majority of instances the rats were subjected to operation at the age of 20 to 30 days, but in some series the operation was done at three different age periods with a view to determining the effect of age on the results. All the operations were performed by Dr. Stotsenburg at The Wistar Institute and I wish to acknowledge with thanks his courtesy in this matter. The method of the operation has been published by Dr. Stotsenburg ('09). The method for removal of the various organs after death is given in my papers published recently (Hatai '13, '14) and any other methods which have not already been given there will be described later.

Usually the operated rats were placed in the same cage with the controls. Thus one cage $(1 \times 1 \times 5$ feet) was occupied by all the individuals belonging to a given litter. If, however, the litter comprised more than six individuals, it was divided between two cages. The operated and control animals were thus treated similarly during the period of observation, and furthermore, the normal rats in the litter were allowed to breed. The object of doing this was to keep the rats under as natural conditions as possible.

Since we already have sufficient data on the growth of the body in weight following gonadectomy, the rats used for the present investigation were not weighed while under observation. The operated and control rats were examined on the same day unless the appearance of disease necessitated an early killing of one or the other. 


\section{FORMULAS}

In order to determine the amount of deviation of any character (e.g., the weight of the organ, external measurements, etc.) in the operated animals from the same character in the controls, there are two methods which are commonly used:

1. The weights of the organs (for example) belonging to both the controls and operated are directly compared, irrespective of the difference in the body weights or ages of the animals employed. So long as the weight of the organ varies with the weight of the body or with the age of the animal, this method is obviously misleading, nevertheless, it has been used by a surprisingly large number of investigators.

2. The second method, which is more commonly employed, is to determine the ratio between the weight of the organ and that of the body and then to compare the magnitude of the ratios for both the controls and the operated. This method is, however, not always satisfactory and indeed in some cases may even lead to an entirely wrong conclusion when the relation between the body weight and the organ weight during growth deviates widely or irregularly from linearity. It is evident, therefore, that the safer method is to make a preliminary study of the phases of the normal growth of the organ or organs of the species in unoperated individuals in order to obtain data by which to estimate the relative deviations more correctly, or at least to avoid any misinterpretations arising from the peculiarities in the growth of the organs with respect to either body weight, body length or age.

Fortunately, in this laboratory we have at hand for the albino rat very adequate data on all the organs and characters under consideration, and furthermore from these data the mathematical formulas have been worked out in order to facilitate interpolation, as well as to study the forms of the growth curves for these characters.

I shall now indicate the method I have employed of computing for any animal examined, the magnitude of the deviations by the use of the formulas. All the formulas which are used in the 
present investigation have been given in my papers recently published (Hatai, '13, '14) and therefore they will not be repeated here.

In determining the deviation of the organs, I have chosen the body length as the basis for the computation since this is the character of the body least subject to incidental modification. As a first step, the weights of the various organs corresponding to the observed body length of the rats under examination are computed by means of formulas. This computation is made for both the controls and the operated animals. The computed values thus obtained usually differ from the observed values, though this difference is not always significant. The differences between the observed and computed values of both operated and controls are now transformed into percentages by taking the computed values as 100 per cent. Thus we obtain two sets of percentage values, one expressing the difference between the computed and observed values in the control rats, and the other expressing the differences between computed and observed values in the operated rats. If the operation has not altered the organs of the animals at all, then these two sets of percentages should be alike within the limits of the normal fluctuations. If, on the other hand, the operation has altered the organs, these two sets of percentages should differ more or less according to the nature of the response to gonadectomy. If we now take the differences of these percentage values as given by the controls and by the operated rats, these differences represent the values by which the operated animals depart from the controls: the body length being used always as the standard for the computations. I have given in table 1 an illustration of the process of computation as here explained.

It must be stated, however, that in the case of the thymus gland, age is taken as the basis for the computation, since the weight of the thymus is much more highly correlated with the age of the rat than with either the weight or the length of the body (see Hatai '14). Again, in the case of the percentage of water in the central nervous system, I have taken the differences directly from the observed percentage values, since the per- 
centage of water is a function of the age of the animal (subject to a slight correction for the absolute weight of the central nervous system-Donaldson) and hence so long as the ages of the control and operated rats are identical, this direct method is sufficiently accurate.

\section{CASTRATION OF ALBINO RAT}

\section{Castration at 16 TO 22 DAYS OF AGE}

This experiment is based on 16 litters comprising 27 controls and 26 operated rats. These 16 litters have been distributed in 6 groups, each containing two or more litters. In all cases the grouping was so made as to bring together those in which the average body lengths of the controls were most similar. The animals were examined 138 days after operation and the results of the observations are given in table 2.

Body length. If we compare the observed body lengths of the control and the castrated rats, it is noted that the castrated have a body length slightly less than that of the controls. This occurs in all six groups and gives an average difference of 4 per cent in favor of the controls. In the two previous studies (Donaldson and Hatai '11, and Hatai '13) we also noticed a similar reaction, that is the body lengths were absolutely shorter in the castrates than in the corresponding controls. We conclude therefore that the castration of young rats hinders the growth of the body in length.

Tail length. It has been noted in my previous study (Hatai '13) that, with respect to the body length, the tail lengths of the castrated rats are slightly greater than those of the controls. The average difference was 5.2 per cent in favor of the castrates. We notice in the present experiment the same degree of deviation; that is, the tails of the castrates are on the average 4.7 per cent longer than those of the controls.

We did not determine the tail length for the rats of the 1909 series. As the tail of the female rat is normally slightly longer than that of the male, this modification of the tail length brings the castrated male rats nearer to the female in this respect. 
Since the anal opening is taken as the point dividing the body from the tail, the question arises whether the longer tails in the operated rats might have been due to the shifting of the anus following removal of the testes, the length of the caudal vertebrae not being altered. As will be seen later, the tail length of the rats whose spermatic cords had been ligated are also longer than those of the controls, to the same extent as in the castrates, despite the fact that these rats have the scrotum of normal size (though filled mostly with fat and connective tissue) and in the normal position. This seems to indicate that in the castrates the elongation of the tail with respect to the body length should not be attributed to a mere shift of the anus. Whatever be the real cause of this phenomenon, we note with interest the definite alteration of this external measurement as a result of castration.

Body weight. The absolute body weights of the castrated rats are slightly below those of the controls. This is to be expected since the body length, which is correlated with the body weight, is less in the castrates than in the controls. When, however, the body weights in the two series are compared with respect to the body length, the castrates show a relatively heavier body weight, though the average difference is only 6 per cent above that of the controls. This difference is certainly small when the normal amount of the fluctuation is considered, nevertheless it occurs in five out of the six groups, and therefore it should not be neglected. In my previous study (Hatai '13) the corresponding difference in favor of the castrates was found to be 3.6 per cent. It seems therefore probable that there is some tendency to a slight overgrowth in body weight with respect to the body length as the result of castration. Although precise tests have not been made, this increase does not seem to be due to an excess of fat, as in the case of the spayed rats, since the post mortem examination shows no evident difference in the fat deposition in the two groups. 


\section{Ductless glands}

Thyroid gland. Table 2 shows that the thyroid of the castrates weighs less than that of the controls. The average deficiency is 21.5 per cent. This deficiency occurs in five groups out of the six. It should be noted, however, that the difference ranges from -0.8 per cent to -90.3 per cent and this wide range of variation must undoubtedly be taken into consideration as the normal variability of the thyroid gland is very high. For this reason an interpretation of the results will be postponed until the relations of the thyroid in the remaining series have been presented.

Suprarenal glands. We notice that these glands show a regular increase in the castrates as compared with the controls. On the average this amount is 17.6 per cent. The amount of the deviation is quite regular, being from 12.8 per cent to 21.4 per cent. Furthermore, the increase is shown in all six groups, thus indicating the significance of the results despite the rather moderate magnitude of the alteration.

Thymus gland. The thymus gland and hypophysis are the two organs which exhibit the most striking reactions after castration. As is shown in table 2, the thymus of the castrates is on the average 61.2 per cent greater than that of the controls. The range of variation is quite uniform with the exception of one undoubtedly abnormal instance (group $X$ ) and extends from 63.5 per cent to 87.4 per cent. If we neglect the unusual instance of 3.2 per cent in Group $X$, we obtain an average increase of 72.7 per cent instead of 61.2 per cent, as given in table 2 .

Hypophysis. The hypophysis also shows a striking alteration as the result of castration. This amounts on the average to 56.7 per cent. The increase is present in all the groups and its value ranges from 45.0 per cent to 67.0 per cent. The present experiment confirms fully the results obtained from the castrated rats during 1912 (Hatai '13) where the increase in the hypophysis was found to be 75.6 per cent.

The somewhat smaller response in the present series may probably be correlated with a slight overgrowth of the body in 
weight as contrasted with that found in the previous study. As will be seen later, there is a close reciprocal correlation between increase in the weight of the body including the fat and the increase in the weight of the hypophysis.

\section{Central nervous system}

Brain weight. As will be seen from table 2, the brains of the castrates show a slight but constant overgrowth when compared with these of the controls. The excess is 2.6 per cent on the average. We have noted in two previous studies a slight decrease instead of an increase, though the amount of decrease was by no means large. Thus we found in the castrates, -3 per cent in the 1911 series (Donaldson and Hatai "11) and -0.3 per cent in the 1913 series (Hatai '13). This lack of correspondence in the results suggests that the differences noted here may be fluctuations merely.

Spinal cord weight. Like the brain, the weight of the spinal cord shows fluctuations which are however slightly greater than those in the brain. On the average we find in this study an increase of 3.3 per cent in the cord weight in favor of the castrates. Further, this increase is shown in five out of six groups. In the 1910 series (Donaldson and Hatai '11) there was found a deficiency of 5.3 per cent; on the other hand, in the 1912 series (Hatai '13) an increase of 3.0 per cent, and finally in the present series an increase of 3.3 per cent. In addition to these results just mentioned, the values obtained from other experiments which will be described, suggest that the results are probably mere cases of fluctuation, and not to be causally related with gonadectomy. This subject will be discussed later.

Water content in the brain and in the spinal cord. The water content of the central nervous system is practically unaltered by castration. We note from table 2 the difference of 0.01 per cent in the case of the brain and 0.20 per cent in the case of the spinal cord, both in favor of the castrates. This result agrees with those of the two previous series, and thus it seems safe to 
conclude that the percentage value of the water content of the central nervous system is not altered by the removal of the testes.

In order to determine the effect of age on the results of castration, a small number of rats were operated upon at two other periods: one lot at 79 to 93 days and the second lot at 208 to 232 days. The results are shown in table 3 and table 4.

\section{CASTRATION AT 79 TO 93 DAYS}

This experiment comprised four litters represented by 6 control and 5 operated rats. These were examined 111 days after operation. We note from table 3 that the results obtained from the present series are not essentially different from those obtained where the rats were castrated between 16 and 22 days of age. In this series we shall comment only on the values obtained for the thyroid and for the central nervous system.

In the case of the thyroid, the increase is 3.8 per cent against -21.5 per cent after early castration, and in the case of the brain and spinal cord, the increases are 0.5 per cent and 0.3 per cent respectively as against 2.6 per cent and 3.3 per cent always in favor of the castrates. These results suggest strongly that the variations recorded in the previous series are probably mere fluctuations.

\section{CASTRATION AT 208 TO 232 DAYS}

This study comprises three litters represented by 7 controls and 8 castrates. The animals were examined at 273 days of age or 55 days after operation. The reactions shown by this oldest series are again similar to those of the two previous series. The highest fluctuations are shown by the thyroid and the central nervous system. The remaining characters show somewhat less difference between the controls and castrated than is found in the two previous series. This slight response may be due either to the shorter interval between operation and examination, or to the advanced age at operation which finds the animals less responsive. 
We note with particular interest the average increase of the thymus gland (53.9 per cent) even at this advanced age. In the normal rat the thymus gland reaches its maximum weight at about 85 days and then begins to diminish in absolute weight very steadily. Indeed at 200 days its loss in weight from the maximum value is nearly 44 per cent (Hatai '14) yet even after this atrophy it appears that the thymus is capable of responding to castration to nearly the same degree as when the operation is performed on younger rats.

\section{Parts of the encephalon}

We have noted that the weight of the brain is not noticeably modified by castration, nevertheless it was thought possible that the relative weights of the different parts of the brain might have been modified. To test this the brain was divided into four parts: cerebrum, stem, cerebellum and olfactory bulbs, in the following way:

1. Olfactory bulbs. The brain is placed with the dorsal side up and with a very sharp scalpel the olfactory bulbs are cut from the rest of the encephalon by section of the olfactory tracts just caudad to the bulbs. The portions thus separated are designated as the olfactory bulbs.

2. Cerebellum. The cerebellum is next removed by severing with sharp scissors the several peduncles.

3. Cerebrum. The cerebrum is separated from the stem by cutting with a scalpel carried in the plane passing just in front of the dorsal edge of the anterior colliculi and just caudad to the corpus mammillare.

4. The remaining portion, caudad to this plane of section, is the stem.

The results of this investigation are given in table 5 . The rats used for it belonged to the series castrated at 16 to 22 days. They were arranged according to age instead of body length, since the relative weights of the parts of the encephalon are more closely correlated with age. 
The total number of the animals used was 22 control and 22 castrated, and these were examined in 6 age groups. In each group the controls and castrated belong to the same litters. As will be seen from table 5, there is practically no difference in the proportional weights of the parts of the brain in the two series. There is however some slight tendency to a relatively smaller weight of the olfactory bulbs in the castrates. The observations are too few and the difference too slight, however, to justify us in putting emphasis on the deviation now. I therefore conclude that so far as the observations go, there is no important difference between controls and castrates in the relative weights of the parts of the brain.

\section{Weights and lengths of certain bones}

In order to determine whether or not castration produces modifications in the skeletal system of rats, some bones, the humerus, radius and ulna, femur and tibia and fibula, were examined. The preparation of the bones was as follows:

The fresh bones were roughly cleaned by dissection and then put into a hot solution of 2 per cent "gold dust cleaning powder" (a commercial preparation) for nearly two hours. The period of course varies slightly according to the size and age of the specimens. As soon as the remaining soft parts were macerated, the bones were cleaned with a strong tooth brush, with an occasional use of the bone scraper. These bones thus cleaned were gently wiped with blotting paper and weighed. This weight is designated here as the 'fresh weight.' The bones were then placed in small vials without corks. After about eight months these bones were again weighed and the amount of moisture was determined-this gave the 'dried weight.' It may be stated that we have had a large experience with the method of preparation in connection with other investigations in this

1 This is not to be confused with the weight of 'dry substance,' to be obtained by subjecting the bones to a temperature of $95^{\circ} \mathrm{C}$., until they reach a constant weight. 
laboratory, and the above method has been found to be perfectly trustworthy for purposes like the present.

The method just given has been applied to all the other series (after spaying and semi-spaying) in which the bones have been studied. The results of this examination are given in table 6. The final averages from table 6 show the following relations:

\begin{tabular}{|c|c|c|c|}
\hline & $\begin{array}{c}\text { BODT LENGTH TO AV. } \\
\text { BONE IENGTH }\end{array}$ & $\begin{array}{l}\text { BODY WFIABT TO } \\
\text { BONE WEIGHT }\end{array}$ & $\begin{array}{l}\text { WATER CONTENT IN } \\
\text { PER CENT } \\
\end{array}$ \\
\hline Controls.. & $1: 0.141$ & $1: 0.0124$ & 25.14 \\
\hline Castrated. & $1: 0.142$ & 1:0.0129 & 27.29 \\
\hline
\end{tabular}

We note from these relations that the difference between the controls and the castrates is very slight, except in the water content in which a difference is clearly indicated. It must be noted, however, that when examined by litters there is a tendency, though slight, for the castrated rats to give constantly a small relative excess in both length and weight of the bones. The small excess is shown in all four groups. At the same time it must be admitted that the difference is certainly much smaller than might have been anticipated from the reports of previous investigators who have discussed the modification of the skeleton after castration.

\section{SPAYING OF THE ALBINO RAT \\ SPAYING AT 19 TO 30 DAYS OF AGE}

The present observations are based on 15 litters comprising 30 controls and 28 spayed. These 15 litters were arranged in 6 groups according to the method adopted for the previous series. The animals were examined from 101 to 190 days after the operation. The results are shown in table 7 .

Body length. If we compare the absolute values of the body lengths of the control and spayed, we note a slightly longer body in the spayed. Though the difference is only 2.5 per cent in favor of the spayed, nevertheless it occurs in five out of six groups, 
while the remaining group shows equality. The significance of this difference is enhanced, despite its small value, by the fact that it has been observed in a previous study (Hatai '13) that the spayed show an increase of 2.7 per cent in body length over that of the controls. From these two studies, which present the same degree of increase, we may safely conclude that spaying stimulates the growth of the body in length. It is interesting to note in this connection that castration as already pointed out (see page 5) has the reverse effect.

Tail length. With respect to the body length, the tails of the spayed are slightly longer than those of the controls. The average increase is 1.9 per cent in favor of the spayed. This increase, however, may not be at all significant, unlike the reaction in the case of the castrates, as it is highly irregular. Moreover, the two other spayed series, which will be presented later, show a decrease in one case and an increase in the other in the length of the tail. These results can best be taken as indicating a statistical variation rather than a significant modification produced by the removal of the ovaries.

Body weight. The body weight with respect to the body length is greater in the spayed than in the controls. The average value gives an increase of 7.3 per cent in favor of the spayed. The range of this increase is high, being from 2.2 per cent to 13.2 per cent, nevertheless it is always in the same direction; that is the spayed have a relatively heavier body. The same response was noted in my previous study on spaying (Hatai '13) though the difference there found was only 3.1 per cent. This low value obtained from the 1912 series was due to the somewhat emaciated condition of some of the rats at the time of killing. We conclude, therefore, that the spayed rats are longer and heavier, while the tail length is not altered by spaying. It should be added here that the spayed rats belonging to the present series did not show as much obesity as those belonging to some previous series (see Stotsenburg '13, and Hatai '13). This fact is important since the variations in the degree of obesity are intimately related with the variations in the weight of the hypophysis. 


\section{Ductless glands}

Thyroid gland. As in the case of the castrates, the thyroid gland of the spayed shows considerable fluctuation in weight. Although on the average spayed have a slightly heavier thyroid (3.3 per cent) nevertheless we find an increase in three groups and a decrease in the remaining three, and in addition to this inconstancy the range of variation is also very great. We shall therefore postpone the discussion of this to a later occasion.

Suprarenal glands. The suprarenal glands of the spayed are smaller than those of the controls. The difference on the average is $\mathbf{1 8 . 5}$ per cent against the spayed. This diminution in the spayed occurs in all six groups, while the range of variation is not so great if we omit one instance, giving an exceptionally small value (group 9, in which the difference is -5.7 per cent). Furthermore, the two remaining spayed series also show a corresponding diminution and thus we may safely conclude that spaying hinders the normal rate of growth of the suprarenal glands in respect to the body weight.

It is interesting to recall that castration tends to increase the weight of the suprarenal glands-just the opposite effect to that produced by spaying. Since normally the female rat has larger suprarenals than the male, and since castration increases, while spaying diminishes the weight of these glands, we see that as the result of gonadectomy the two sexes tend to approach one another in this character.

Thymus gland. The thymus gland of the spayed shows a most striking alteration. In some cases its increase runs as high as in the castrates, and indeed on the average it shows an increase of 58.3 per cent in favor of the spayed. This increase in the spayed occurs in all six groups, and thus the causal connection between the greater size of the thymus and removal of ovaries is clearly shown. The range of increase, 34.2 per cent to 75.8 per cent, was higher than might be anticipated on account of the two groups in which the increase was rather small.

Hypophysis. The hypophysis shows a distinct increase of 8.9 per cent in the spayed rats. This increase ranges in the 
several groups from 0.3 per cent to 21.6 per cent. However, it occurs in all the groups and furthermore it has been noted in my previous study (Hatai '13). It is interesting to observe that in general the increase of the hypophysis is negatively correlated with gain in body weight.

\section{Central nervous system}

Brain weight. The relative brain weight of the spayed rats is slightly heavier than that of the controls. On the average the difference is 1.3 per cent, and it occurs in five out of six groups. The other two studies on spayed rats, to be presented later, give in one study similar values, and a decrease in the other. These irregularities suggest that the increase recorded in the present series should be regarded as a fluctuation.

In my previous study (Hatai '13) the spayed rats showed a decrease of 0.4 per cent in the weight of the brain. This disagreement between the results of two successive years supports the view thatowe are here dealing with a fluctuation only.

Spinal cord weight. The spinal cord of the spayed rats shows a still greater relative increase than does the brain. On the average, the spayed shows 2.5 per cent increase, and furthermore this occurs in five out of the six groups. A slight increase in the spinal cord weight has also been observed in a previous study (Hatai '13) and in view of the fact that the increase occurs in all operated animals (see all the experiments reported in this paper) we are hardly justified in regarding it as a mere fluctuation, though at the same time there does not seem to be any reason to expect this increase. I shall therefore leave this point without attempting any interpretation at the present time.

Percentage content of water in the central nervous system. The amount of water present in both the brain and spinal cord is not altered by the removal of the ovaries. We note from table 7 only an insignificant difference between the control and spayed rats. This result agrees fully with that of the two previous studies and we may conclude therefore that the water content of the nervous system remains unmodified. In addition I have 
studied two other series represented by the albino rats spayed at more advanced ages: (1) Spayed at 97 to 119 days and (2) spayed at 172 to 195 days of age.

\section{AFTER SPAYING AT 97 To 119 DAYs OF AGE}

This series comprises five litters containing 9 controls and 8 spayed. These rats were examined 100 days after spaying. The results of the operation are shown in table 8. We find in this series a general agreement with the previous results.

Body length. The absolute value of the body length of the spayed is slightly greater than that of the controls. This agrees with the previous observation.

Tail length. The relative tail length of the spayed is slightly shorter (1.5 per cent) as against the slight increase in the previous series. This disagreement suggests that the variations in tail length are merely fluctuations.

Body weight. The body weight of the spayed rats shows a slight relative increase and thus agrees with the previous observations.

Thyroid gland. The thyroid of the spayed shows 50.6 per cent decrease as against 3.3 per cent increase in the previous series. This disagreement indicates that the variations shown by this organ are probably fluctuations or dependent on conditions not yet recognized.

Thymus gland. We note 39.6 per cent increase in the spayed. This result agrees with the previous observations.

Hypophysis. The hypophysis of the spayed shows 7.8 per cent increase. The results agree with the previous observations.

Brain weight. As before, there is no difference in the weight of the brain between the controls and the spayed.

Spinal cord weight. There is a very slight increase of 1.5 per cent in the weight of the spinal cord of the spayed. This agrees with the previous observations.

The percentage of water in the central nervous system shows no significant variations. 


\section{AFTER SPAYING AT 172 TO 195 DAYS OF AGE}

This series comprises three litters containing 9 controls and 7 spayed rats. The rats were examined 27 to 60 days after operation. The results are shown in table 9. This series shows alterations essentially similar to those found in the two preceding series, and therefore a detailed description may be omitted.

We note with special interest the reaction shown by the thymus gland after spaying. It has been stated already that the thymus gland at. 200 days is nearly 44 per cent less than at the maximum stage (at 85 days). Thus even in this advanced stage of involution the thymus gland responds to spaying and shows an average increase of 27.5 per cent. In one case, group 14 , the increase is as high as 60.8 per cent, or almost as great as in the rats operated at 19 to 30 days. All the other characters show the alterations we should expect from the two preceding series.

\section{Parts of the encephalon}

The parts of the encephalon of the spayed rats have been examined to see whether or not any differences in the relative weights between the spayed and controls can be detected. The methods of dissecting the brain, as well as of grouping the rats, were the same as used in the case of castration. The results of the investigation are given in table 10. As will be seen from the table, there is no significant difference in the relative weight of the parts of the brain in the spayed and in the controls. If we examine the different groups we note some tendency to relatively small olfactory bulbs in the spayed. The difference, however, is too slight to be regarded as of value. We conclude therefore that removal of the ovaries has no marked effect on the relative weights of the parts of the encephalon.

\section{Weights and lengths of certain bones}

The weights and length of the bones of the spayed, together whith those from the controls, were investigated. The technique used and bones examined were the same as in the case of the castrated rats. The results of the investigation are given in 
table 11. From the final average given in the table we find the following relations:

\begin{tabular}{|c|c|c|c|}
\hline & $\begin{array}{c}\text { BODY LENGTH TO AV. } \\
\text { BONE LENGTH } \\
\end{array}$ & $\begin{array}{l}\text { BODY WEIGHT TO } \\
\text { BONE WEIGHT } \\
\end{array}$ & $\begin{array}{c}\text { WATER CONTENT IN } \\
\text { PER CENT }\end{array}$ \\
\hline Controls ............ & $1: 0.146$ & $1: 0.0134$ & 23.44 \\
\hline Spayed.............. & $1: 0.148$ & $1: 0.0128$ & 25.35 \\
\hline
\end{tabular}

From the above it appears that the differences in the relative values between the controls and the spayed are very slight. Nevertheless, we note as in the case of the castrates, that the spayed give a slightly higher value in the case of the bone length. In the case of the bone weight, the spayed rats give a less value. In this instance the weight relation is due to the abnormal fat deposition which follows spaying. According to the formula, a body length of $188 \mathrm{~mm}$. (that of the spayed) should give a body weight of 170 grams, while the observed body weight of the spayed is 186.1 grams, thus showing a difference of more than 9 per cent. If therefore we take a corrected body weight of 170 instead of 186.1 grams, the ratio between the body and bone weight becomes 1:0.140, or the spayed have a slightly heavier relative bone weight than that of the controls.

The water content is distinctly greater in the spayed, thus agreeing with what was found for the castrates. We conclude then that gonadectomy in the rat tends to give rise to very slightly longer and heavier bones, which in turn have a higher water content than those of the controls.

\section{SEMI-CASTRATION OF THE ALBINO RAT}

AFTER SEMI-CASTRATION AT 17 TO 27 DAYS OF AGE

This series comprises 15 litters containing 22 controls and 24 semi-castrated rats. These 15 litters were placed in five groups according to the method previously employed. The results are given in table 12 .

Body length. The semi-castrated rats did not grow in length as much as the controls. In this respect the semi-castrated are 
similar to the castrates. On the average we find that the semicastrated give a body length of $209 \mathrm{~mm}$. against $217 \mathrm{~mm}$. for the controls; a differentce of 3.7 per cent in favor of the controls. This relation is true not only on the average,-but appears also in four out of the five groups. In view of these uniform results, we draw the tentative conclusion that semi-castration hinders slightly the normal growth of the body in length.

Tail length. In four out of five groups the tail length of the semi-castrated is greater than that of the controls. On the average, the difference is 1.9 per cent in favor of the semi-castrated. It is evident that the amount of increase is hardly one third of that given by the castrates, and further the fluctuation is much greater than that of the castrates. Moreover, since we find a decrease in the relative length of the tail in the semi-castrates given in the next series, we conclude that the differences represent mere fluctuation, and that the length of the tail is not modified by semi-castration.

Body weight. The relative body weight is slightly greater in the semi-castrated than in the controls. We find on the average a difference of 1.9 per cent in favor of the semi-castrated. The increase is shown in five out of six groups, and further the range of variation is not large. This seems to be an instance of a slight tendency to an increase of the body weight as the result of the operation.

Testes. The surviving testis of the semi-castrate shows a distinct and uniform increase in weight over that of the normal control testes. The increase is on the average 14.2 per cent. This is also shown in all the groups and ranges from 6.1 per cent to 23.8 per cent. It is important to decide whether this increase is represented by the germinal tissue or by the interstitial tissue, or by both. It is generally held that the structure which is responsible for the internal secretion of the testis is the interstitial and not the germinal tissue. If this be true, and if we assume that the increase in this instance is represented by the interstitial tissue alone, then the percentage increase of the latter structure will be considerably larger than that indicated 
by the values given here. We shall take up this subject later on. utilizing Hofmeister's observations ('72) on the interstitial tissue of the human testes.

\section{Ductless glands}

Thyroid gland. The thyroid gland of the semi-castrated shows an average increase of $\mathbf{1 6 . 4}$ per cent above the controls. Here again, as in the previous observations on the thyroid, the range of variation is very great, being from -37.3 per cent to 41.0 per cent, and furthermore in the rats semi-castrated at 81 days, and which will be described later, the thyroid shows 29.6 per cent decrease instead of an increase. It is not therefore possible at the moment to correlate the changes in the thyroid with this operation

Suprarenal glands. The relative weight of the suprarenal glands shows a slight alteration in the semi-castrated, giving an average increase of 2.7 per cent in their favor. This low value is due to an exceptionally small response given by group $5(-0.9$ per cent). If we neglect this exceptional case, the average rises to 3.5 per cent. The increase in the semi-castrated is shown in four out of five groups, and further the range of variation is not so large, particularly if we neglect the very small value given by group 5. Nevertheless, the increase is too slight to warrant us in putting much weight upon it. However, some tendency to an increase as the result of semi-castration can not be denied.

Thymus gland. Curiously enough, the thymus gland of the semi-castrated rats shows an average decrease of 16.1 per cent. The decrease occurs not only in the final average, but also in four out of the five groups. The range of variation is not large in comparison with the variations of the thymus glands belonging in other series. It ranges from -12.8 per cent to -30.0 per cent against the semi-castrated. On the other hand, we find in the rats semi-castrated at 81 days 9.8 per cent increase of the thymus - the exact opposite-and thus the interpretation is at present impossible. This is the only instance in all the experiments recorded in the present paper in which a decrease of the thymus gland as the result of the operation has been found. 
Hypophysis. The hypophysis shows an average increase of 10.1 per cent as the result of semi-castration. The range of variation is great and lies between 0.5 per cent to 29.8 per cent. Semi-castration at 81 days shows 0.25 per cent decrease, equivalent to no change (see table 13). In view of this high variability of reaction all we can note is a tendency to overgrowth of the hypophysis as one result of this operation.

\section{Central nervous system}

Brain weight. We find that the weights of the brain in the controls and semi-castrated do not show any significant difference. The average value gives -0.5 per cent against the operated rats. There is perhaps a very slight tendency to reduction in the brain weight of the semi-castrated, as it occurs in four out of the five groups. However, the difference is in many cases less than one per cent and we thus conclude that semi-castration produces no important alteration in the weight of the brain.

Spinal cord weight. The spinal cord of the semi-castrated rats with respect to the body length is slightly but constantly larger than that of the control rats. Its increase is shown in all five groups and the final average shows 2.2 per cent in favor of the semi-castrated. This agrees with the results of all the experiments so far presented.

Percentage of water in the central nervous system. In this character the difference between the operated and control rats is very small. We therefore conclude that the proportion of water which is present in the central nervous system is not altered by semi-castration.

\section{AFTER SEMI-CASTRATION AT 81 DAYS OF AGE}

The number of rats comprised in this series is rather small ( 6 controls and 5 semi-castrated) but the results show a close agreement with those rats from which one testis was removed at 17 to 27 days. The data are presented in table 13 . It is only necessary to point out in this series also that the surviving testis shows a typical increase in size. The increase is 15.1 
per cent contrasted with 14.2 per cent for the previous series. The alterations shown by the other characters are similar to those found in the series operated at an earlier age, and therefore we conclude that the effects of semi-castration at 81 days are nearly the same as those found when the operation is made at 17 to 27 days, with the exception of the hypophysis, in which the rats operated at the earlier period show a slight excess.

\section{Parts of the encephalon}

The parts of the encephalon of the semi-castrated rats have been investigated. The technique and method of grouping are the same as before (see page 10.) The rats employed for this study were those semi-castrated at 17 to 27 days with their controls. The results are given in table 14. As will be seen from the table, there. is no significant difference in the relative weights of the parts of the encephalon in the control and the semi-castrated We therefore conclude that the relative weights of the different parts of the encephalon are not modified by this operation.

\section{THE LIGATION OF THE SPERMATIC CORD}

Since the removal of the testes produces striking modifications in the external characters, as well as in some organs, and since the removal of one testis alone does not produce any noticeable alterations, presumably owing to the compensatory growth of the interstitial tissues of the surviving testis, it was thought interesting to determine the effect of ligation of the spermatic cord, an operation which interrupts not only the vas deferens but also the accompanying vessels and nerves. Although this operation leaves the testes in place, not only may their growth be stopped, but they may undergo various atrophies or degenerative changes as a consequence of it. The operation was made on a small number of rats; 6 operated and 6 controls. The results are shown in table 15. The operated animals were allowed to live a little more than three months. Examination of results reveals the fact that we must treat the 
data in two groups: Group 1 comprises those operated rats whose testes, though typical in form, are yet small, pale in color, semi-transparent and filled with an abundance of liquid. Thus group 1 shows an abnormal condition of the testes, though their form was normal. Group 2 comprises those operated rats whose testes have been nearly completely absorbed.

Group 1. In this group the testes of the operated rats show a decrease of 31.6 per cent, nevertheless the typical form was still maintained. Although no histological examinations have as yet been made, it appeared to me that the germinal tissueswere probably completely absorbed, or at least altered beyond recognition. As will be seen from table 15 , the characters usually affected by castration were not noticeably modified. This negative result suggests that the interstitial cells of the testes were very likely intact or might even have proliferated.

Group 2. On the other hand, in those operated rats whose testes have been nearly completely absorbed ( -93.2 per cent) alterations characteristic of the castrated rats are plainly to be observed. A slightly longer tail, larger suprarenal glands, thymus and hypophysis, definitely supports this conclusion. We conclude, therefore, that ligation of the spermatic cord is similar to castration in the reactions which it causes, if the testes are absorbed, but its reaction is negative if the testes persist, even though they may be materially reduced in size. Under these conditions it is inferred that the germinal tissue has been destroyed, while the interstitial tissue remains either in its normal quantity or possibly is hypertrophied.

SEMI-SPAYING OF THE ALBINO RAT

AFTER SEML-SPAYING AT 38 TO 51 DAYS OF AGE

This experiment comprises a rather small number of rats, and the discussion of the effects of the. operation will be limited to those characters only which showed undoubted alterations. The agreement in the results betweeen the present series and that previously studied (Hatai '13) is clear. The results are shown in table 16. 
In general, we may say that the semi-spayed show no significant response except in the increased weight of the surviving ovary. The large difference shown by the thyroid gland must for the present be credited to its high variability. The slight increase of the other ductless glands may be considered a general reaction common to all operated rats. On the other hand, the weight of the surviving ovary is most striking, showing an average increase of 131.8 per cent. Thus the one ovary of the semi-spayed weighs more than twice the normal ovary. In my previous experiment the increase of the surviving ovary was found to be 73.1 per cent; the present experiment thus gives the greater increase. No explanation for the amount of increase in the surviving ovary can be given at the moment, and we must be content to call attention merely to the striking character of the reaction.

The lengths and weights of the long bones, together with their water content, after semi-paying

The weights and lengths of these bones, together with their content of water have been investigated. The technique used is the same as that employed in the preceding cases. The results are given in table 17 . From the final averages in the table we obtain the following relations:

\begin{tabular}{|c|c|c|c|}
\hline & $\begin{array}{l}\text { BODY LENGTH TO AV. } \\
\text { BONE LENGTH }\end{array}$ & $\begin{array}{l}\text { BODY WEIGET TO } \\
\text { BONE WEIGET }\end{array}$ & $\begin{array}{l}\text { WATER CONTENT IN } \\
\text { PER CENT }\end{array}$ \\
\hline Controls ............. & $1: 0.140$ & $1: 0.0141$ & 26.985 \\
\hline
\end{tabular}

From the above we find that the relation of the body length to the bone length is identical in the operated and controls. The ratio of the body weight to the bone weight is distinctly lower in the semi-spayed rats. This is undoubtedly due to the emaciation of the body weight of the control rats, as can be seen from the relation given by the length and weight of the body. Thus if we take the ratio between body length and bone weight, we 
obtain 1:0.0126 in the case of the control and 1:0.0125 in the case of the semi-spayed. It is therefore safe to conclude that as compared with the controls, semi-spaying does not modify the bones either in weight or in length with respect to the weight and length of the body. We note also the practical identity in the water content of the bones in semi-spayed and controls.

\section{THE ISOLATION OF THE OVARIES}

Since the complete removal of the ovaries alters seriously several bodily characters and organs, and since semi-spaying does not produce any noticeable alterations, owing probably to the compensatory growth of the surviving ovary, it was thought interesting to determine the effect of the removal of the one ovary, combined with a severance of the other ovary from the uterus. This experiment has been made with a small number of rats and the results are shown in table 18.

As will be seen from this table, the result of the operation is not materially different from the case of the semi-spaying. No significant alterations are produced in any characters except the weight of the ovaries. We find here an average increase of 51.3 per cent in the surviving ovary. The amount of increase is not so large as in the case of the semi-spayed just described. The smaller alteration is to be expected, as of course the ovary is in the first instance severed from its normal connections,blood supply, etc., and thus subjected to unfavorable conditions. In some instances the ovary was enclosed in a capsule containing fluid, and these cases showed unmistakable signs of absorption, the color was pale and the lobulation wanting.

\section{DOUBLE ISOLATION OF THE OVARIES}

From the results just described, we should anticipate that the isolation of both ovaries from the uterus would not be followed by any marked alterations. It was thought best, however, to test this assumption and therefore the following short experiment has been made. The results are given in table 19. 
As had been anticipated, no notable alterations were shown as the result of the isolation of both ovaries. The responses exhibited by the various characters are very small, and particularly when we consider the small number of rats in the series, these modifications can all be neglected. We however note with some interest a slight increase of the ovaries (14.0 per cent) in the operated rats, but whether this increase is a consequence of the operation or a mere fluctuation, cannot be decided without more evidence.

\section{GENERAL DISCUSSION OF THE RESULTS OF GONADECTOMY}

So far I have merely presented my results without either interpretation or comment, save in the case of the external characters. I wish now to discuss these results and if possible to interpret the alterations following gonadectomy.

For convenience I give in table 20 the percentage deviations of the various characters in the operated rats from those in the controls. The external characters, such as absolute body length and body weight, and also body weight and tail length relative to body length have been briefly considered in the case of each series, and appear to be particularly related to changes in the hypophysis. It is especially with the members of the endocrene system, so far as we have examined them, that we are at present concerned.

Thyroid gland. On the average the amount of deviation in the weight of the thyroid gland of the operated from that of the controls ranges from 34 per cent to -51 per cent (see table 20). On account this high variability, as well as the absence of uniformity of response to the same operation, no definite conclusions can be drawn from our results touching the effect of gonadectomy on it. Turning to the literature, we find that Tandler and Grosz ('13) observed constantly a small thyroid gland in eunuchs. Biedl ('13) mentions finding a small thyroid in one castrated dog. Soli ('09) found a considerable variation in the weight of the thyroid in capons. Out of the nine pairs which he examined, four showed an increase and five a decrease in the castrated 
compared with the controls. Soli however found a constant increase in the weight of the thyroid in the castrated rabbits (numbers are not given) when examined three months after castration, but this in turn was followed by a decrease, so that at the end of the experiment the castrated rabbits had smaller thyroids than the controls. Engelhorn ('12), on the other hand, found an hypertrophy of the thyroid after spaying in women and in rabbits. Thus, so far as the previous investigations are concerned, the effect of gonadectomy on the size of the thyroid is not determined.

In view of the great variability of the thyroid in weight in both men and animals, and in view of the small number of animals used by most investigators and the almost complete absence of data for the normal animal, as well as the inconstancy of our own results on the albino rat, we conclude that no general statement as to the effect of gonadectomy on the thyroid is justified at present.

The thyroid gland of the albino rat presents, however, several interesting features worthy of remark. I have determined (Hatai '13a) that the hypophysis and the suprarenals of the albino rat show distinct sexual differences in their weights. The thyroid gland, however, does not show any sex difference in weight. Moreover, for any given body weight, the weight of the thyroid is practically identical in the (domesticated) albinos and (the wild) norway rats, while the other ductless glands show distinct weight differences in these two forms. Thus in the albino the thyroid glands shows no response to the changes in the surroundings (domestication) nor variations according to the sex similar to some other ductless glands.

Whether the thyroid of the rat is physiologically less important than some of the other ductless glands cannot be decided from such simple observations, nevertheless it is of interest to note that the ill effects of thyroidectomy in the rat are remarkably slight (see Vincent '12). One might suspect that the high variability of the thyroid gland was due in part to pregnancy in the females. I have examined my data with this idea in mind, but have failed to find any correlation between pregnancy and 
thyroid weight. As a matter of fact, the variability of the gland is as large in the males as in the females.

Suprarenal glands. The effects of gonadectomy on the size of the suprarenal glands have been studied by several investigators. Feodossiew ('06) found an enlargement of the suprarenals in spayed dogs. Von Schenk ('10) found histological evidence of hyperfunction of the gland in spayed rabbits. He further noted an enlargement of the gland as indicated by the fact that the areas of the sections in the operated are greater than those of the controls. Von Schenk, however, did not record any weights. Marrassini and Luciani ('11) noted in spayed guinea-pigs and rabbits an enlargement of the suprarenals.

As the result of castration, Soli ('09) found a diminution of the suprarenals in the chicks, and in guinea-pigs and rabbits. In the latter however the suprarenals soon after operation showed a very slight inerease which was followed by a distinct diminution in a latter stage. Marassini and Luciani ('11) on the other hand found a considerable increase in castrated rabbits and in guineapigs ${ }^{*}$ when compared with their respective controls. Stilling ('98) found an enlargement of adrenals in male rabbits during the breeding season. Kolmer ('10) who studied the histology of the suprarenal glands of guinea-pigs, shows clearly an intimate relation between the sex glands and the suprarenals. $\mathrm{He}$ states that there exist definite cyclical changes of the suprarenals following corresponding changes of the sex glands in functional activity.

It is evident from this that the suprarenal glands are intimately related to the sex glands, both in males and in females. My own investigations also show clearly such relations between the two sets of glands in the rats; i.e., the suprarenal glands exhibit characteristic alterations after gonadectomy. It has been found that the suprarenal glands of the castrated rats exhibit an increase of 8.5 per cent to 17.6 per cent on the average, while those of the spayed rats show a decrease of 5.3 per cent to 25.0 per cent compared with their respective controls. These variations in the reaction in the two sexes are very regular and occur in all series and in most groups in each series. Why the suprarenals 
respond differently in the two sexes as the result of gonadectomy cannot be explained at present, and we therefore merely note this singular phenomenon. There are no other corresponding observations on rats in the literature, so that our results must be compared with those obtained from other animals.

It is interesting to note, as previously stated, that Soli ('09) records a reduction of the suprarenals as the result of castration, while Marrassini and Luciani ('11) using the same species of animals, noted an increase. These diametrically opposed results may mean that the individual variation of the suprarenals is greater than that produced by castration, or that the suprarenals may not respond similarly at different seasons, or in the presence of different diets. As will be seen later, these investigators obtained after castration opposite results for the size of the hypophysis also. We must therefore await the results of further experiments with a much larger number of animals belonging to the species studied, maintained under very definite nutritive conditions, before endeavoring to reach a conclusion.

In this connection it is important to point out once more that the size of the suprarenal glands in rats differs strikingly according to sex (Hatai '13). The female rats have considerably larger glands than the males. This sexual difference is evident prior to sexual maturity. Gonadectomy in the male increases the weight of the suprarenals at the same time that gonadectomy in the female reduces the weight, thus bringing the two sexes nearer together in this character. Moreover, we notice in several other instances after gonadectomy, the similar phenomenon of the approach of characters which are differently modified in the normal rat according to sex. The weights of the suprarenals are not altered to any noticeable extent by partial gonadectomy, either in the males or the females.

Thymus. The effect of gonadectomy on the size of the thymus has been studied by numerous investigators. Calzolari ('98) found the thymus in the castrated rabbits strikingly enlarged. He considers that the normal atrophy of the thymus is delayed by the removal of the testes. Henderson ('04) obtained similar results in rabbits, guinea-pigs and cattle. Goodall ('04) noted 
also an enlarged thymus in castrated guinea-pigs. Hammer ('05) and Tandler and Grosz ('07) found the thymus enlarged in eunuchs. Further, Soli found the same ('09) in chicks and rabbits; Marrassini ('10) in chickens, and Gellin ('10) in both sexes of rabbits obtained similar results. Still other investigators have noted the hypertrophy of the thymus after gonadectomy and their papers are cited in the works of Biedl ('13) and of Vincent. ('12), to which the reader is referred.

It is clear, therefore, that all the investigators agree that gonadectomy increases the size of the thymus in both sexes. As can be seen from table (20), my own investigations on albino rats are in full accord with this result. The weight of the thymus after gonadectomy is almost twice that in the control rats, and furthermore the enlargement occurs in all the series with the exception of the semi-castration series at 17-27 days in which series the reaction is anomalous. We further note that gonadectomy in young animals not only enlarges the thymus and delays its normal involutionary process, but that the gland responds even after it has atrophied to a considerable extent. The experiments upon the rats whose ages were about 200 days show this clearly (pp. 9 and 17). Although we have not examined histologically the normal thymus at 200 days, nevertheless its gross appearance shows that much of the mass is represented by connective tissue. Yet even in such a highly atrophic stage, the thymus can respond nearly as well as when gonadectomy has been performed at a much earlier age.

Hypophysis. The alterations in the size of the hypophysis following gonadectomy have been much studied and we are therefore in a position to discuss these alterations somewhat fully.

Fichera ('05) has shown that the removal of the testes in fowl and cattle enlarges the hypophysis. $\mathrm{He}$ also has shown that spaying produces similar enlargement of the hypophysis in rabbits and guinea-pigs. Fichera considers this hypertrophy of the hypophysis as a physiological compensation, supplementing the loss of the sex glands. Fichera's observations were confirmed by numerous investigators using not only the same species, but also several other kinds of animals. We shall cite only a few of 
the investigators whose work seems most closely related to our own, and for the full bibliography refer the reader to the works of Biedl ('13) and Vincent ('12). Enlargement of the hypophysis has been reported by Parhon and Goldstein ('05) in spayed rabbits and dogs, by Cimoroni ('08) in castrated rabbits and dogs; by Kon ('09) and by Tandler and Grosz ('10) in both men and women; by Hatai ('12) in castrated rats; by Zacherl (cited by Biedl '13) in both male and female rats; and by Soli ('09) in castrated fowls and rabbits. Livingston ('14) finds an enlarged hypophysis in spayed rabbits, but not in castrated. Lastly, this present experiment gives again an instance of enlarged hypophysis in the male albino rat after castration (table 2, 3 and 4) while spaying also is followed by an increase, which, however, is only slight.

At the same time, there is an almost equally numerous group of investigators who have not found an enlargement of the hypophysis after gonadectomy. For instance, Pirsche ('02) did not obtain any enlargement of the hypophysis from castrated guinea-pigs, but at the same time he found a noticeable increase in the body weight. At autopsy he did not notice any unusual deposition of fat. Barnabo ('08) failed to find an enlargement of the hypophysis in castrated albino rats, though he found an enlargement in a rat, one testis of which had been removed and the vas deferens of the other testis ligated. Marrassini and Luciani ('11) using fowls, cattle, guinea-pigs and rabbits (the kinds of animals used by Fichera) failed to notice an hypertrophy of hypophysis, though they noted the enlarged suprarenal glands. Hatai ('13) noticed in the spayed albino rats an increase of the hypophysis which was small as compared with that following castration. Livingston ('14) in a large number of rabbits failed to find an enlargement of the hypophysis in the castrated males, but noted an overgrowth of the body in weight. In the spayed female rabbits, however, Livingston found a noticeable degree of hypertrophy of the hypophysis, but failed to obtain an overgrowth in body weight. Lastly, my own present experiment fully confirms the findings of the previous experiment: that is, in the castrated rats the hypophysis enlarges very strikingly, while the 
growth of the body is nearly normal. On the other hand, in the spayed rats the hypophysis shows only an insignificant increase, but this is accompanied by greater growth, both in body weight and in body length.

I have mentioned already the experiments of Barnabo and of Zacherl, both of whom used albino rats. Since my own observations are based entirely on gonadectomized albino rats, and since the foregoing is the only work with which our own can be directly compared, it will be worth while to review in some detail the results obtained by these two investigators.

Barnabo's ('08) experiments were as follows:

Series 1. Bilateral section of vas deferens. This series comprises three rats.

Series 2. Section of vas deferens on one side and castration on other. This series comprises two rats.

Series 3. Bilateral castration. This series comprises three rats.

Barnabo's operations were performed on sexually mature rats (112 grams in average body weight) and the period between operation and death was on the average 76 days. As long as we have made no experiments corresponding to Barnabo's Series 1 and 2, we shall pass them by and consider only the results obtained from his Series 3. There we find the average weight of the hypophysis as reported by him was 0.015 grams in rats with a final body weight of 151 grams. Barnabo concludes that the weight of the hypophysis is not altered as the result of castration. No data are given regarding the control rats, and it is merely stated "Per altro controllo mi sono poi servito di animali normali." However, according to our formula (Hatai '13) the weight of the hypophysis given by Barnabo is almost 150 per cent heavier than it ought to be for the body weight given. For this peculiar result no satisfactory explanation can be given, but I venture to suggest that it is just possible that Barnabo did not realize the existence of the striking sex difference in the weight of the hypophysis, and by an oversight compared the weight of the hypophysis in the castrated rats with that in normal females, in which case but slight difference might appear, as at 
this period the weight of the hypophysis in the female is more than twice that in the male (Hatai '13). In any case, the number of rats used by Barnabo is certainly too small to furnish the basis for any definite conclusion.

Concerning Zacherl's work, we have too little information for criticism. The following is Biedl's ('13) statement concerning Zacherl's work: "Bei Ratten tritt nach der Kastration, wie aus den Versuchen, welche Dr. Zacherl in unserem Institute ausgeführt hat, hervorgeht, konstant eine Volumzunahme der Hypophyse ein, u. zw. sowohl bei männlichen, wie bei weiblichen Tieren." Nothing is given regarding the number of rats used for either control or operation and no numerical data concerning the weight of the hypophysis are given, so that the extent of the alteration cannot be determined.

So far as I am aware, these are all the statements we have regarding the effect of gonadectomy in the albino rat on the weight of the hypophysis, and for reasons already given, we must await further work before explaining the differences between the results of Barnabo on the one hand and those of Zacherl and ourselves on the other.

The brief review of the literature given above reveals the fact that the findings as to the effect of gonadectomy on the size of the hypophysis are diametrically opposed to each other. Probably the contradictory results obtained may be traced to one or more of three causes:

(1) Insufficiency in the number of animals used.

(2) Variations in the weight of the hypophysis arising from confusion of the sexes or from the use of different litters, or still more from the use of different strains of the same race.

(3) True variations in the response of the hypophysis associated with differences in the reponse of the body to gonadectomy.

The first two suggestions have been discussed in my previous paper (Hatai '13) and I will therefore limit my comments here to the third cause named.

It is highly probable that the hypophysis may not respond always in the same manner, but vary in its response according to the condition of some other parts of the body. For instance, 
I have often noted that some spayed rats presented a considerable increase in the weight of the hypophysis when these animals failed to show any overgrowth and obesity. The reaction of the hypophysis in this instance is similar to that in the castrated rats. Similarly, the castrated rats give a very slight or practically no increase in the weight of the hypophysis, when these show, as they sometimes do, a marked obesity. In this case the reaction of the hypophysis is much the same as that of the typical spayed rats. Such instances are not at all infrequent. In fact, in the series here described all the female rats whose ovaries were removed gave much greater increase in the weight of the hypophysis than those belonging to the previous series (Hatai '13). The difference in the response in the two series is explained by the fact that the spayed rats belonging to the earlier experiment (1912 series) showed considerable obesity, while those belonging to the present series did not, although the body had gained both in weight and in length. It seems therefore probable that the size of the hypophysis and body changes, especially fat deposition, are inversely related.

The evidence just given suggests that the contradictory findings by various observers may be due in part to these differences in response shown by the body as a whole, or by some of the other ductless glands. It is probable therefore that if the three conditions mentioned above were carefully regarded we might in the future obtain more harmonious results. Since this survey indicates that the weight of the hypophysis and of the body are reciprocally related, I wish to show how far this suggestion may be used to explain some discrepancies already found in the literature.

We have noted that Pirsche ('02) found an overgrowth of the body in weight in the castrated guinea pigs, but did not find the enlargement of the hypophysis. Pirsche's observation is certainly contrary to the observation of Fichera ('05) who found an enlarged hypophysis, but possibly the discrepancy may be traced to the different reactions of the body in weight. Unfortunately Fichera does not give us any information regarding the growth of the body and thus we are unable to test the point in this case. 
However, Livingston's ('14) experiments on rabbits demonstrate the reciprocal relation in the weight of the hypophysis and of the body, and thus it appears probable that different results obtained by others who also used rabbits, may be traced to the differences in the response of the body. There seems to be analogous variations in the case of the other ductless glands. Paton ('13) gives the following instance of a typical response of the testes after thymectomy in guinea-pigs:

When studying the action of testes and thymus on growth, I found that one guinea pig in my series, after removal of the thymus, hardly grew at all, although remaining quite well and active. When it died at over four months old, it was like an animal about a fortnight old, and the testes were in size and structure those of an animal of the same age. They had undergone no compensatory hypertrophy, as they usually do, and the result had apparently been arrest of growth which occurs when thymus and testes are removed together.

I have shown elsewhere (Hatai '13) that in albino rats the hypophysis of the female is more than twice as heavy as that of the male. This sexual difference is evident prior to sexual maturity. Our present observations show this sexual difference to exist in the norway rats, although it is slight in amount. Whether or no a sexual difference exists in other mammals has still to be determined. Whatever may be the true function of the hypophysis and its relation to the body, we have interesting quantitative relations between the size of the hypophysis and size of the body. The clinical as well as the experimental evidence (Cushing '09, and Vincent '12) shows with a high degree of probability that 'hyposecretion' of the hypophysis produces an abnormal deposit of fat and a tendency to gigantism. Thus if a compensatory growth of the hypophysis does not follow, as is the case after spaying, the product of the unaltered gland must be employed for two purposes, one to replace the ovarian hormone, and two, for the normal uses, whatever these may be. Spaying thus appears to overtax the unmodified gland, and consequently to produce phenomena similar to those following hyposecretion. On the other hand, compensatory hypertrophy of the hypophysis in the male albino rats after castration appears 
to prevent the phenomena of hyposecretion, and consequently the body changes are absent. The typical cases mentioned above may be interpreted on the same principle. The results of semi-spaying and of semi-castration in the albino rat gives still further evidence in support of the view just presented. Partial gonadectomy produces neither an enlargement of the hypophysis, nor abnormal fat deposition in the body. This is explained by the fact that the remaining sex gland undergoes a compensatory hypertrophy, and thus the normal secretory function is performed adequately.

Ovaries. A compensatory hypertrophy of the surviving ovary after semi-spaying has been noted by several investigators. Bond ('06), Carmichael and Marshall ('08) and Fichera ('10) all reported this in semi-spayed rabbits. In my previous paper (Hatai '13) I have also shown the compensatory hypertrophy of the remaining ovary in the semi-spayed albino rat. The present investigation confirms the previous results, and indeed the semispayed rats of the present series give a surviving ovary of more than twice the normal size. This compensatory growth of the ovary evidently prevents all body changes after semi-spaying, as I have not been able to find any noticeable alterations in the other characters examined. I have not made any histological examination to determine exactly what tissue is responsible for this enlargement of the ovary. However it is probable that this increase is caused by the overgrowth of the interstitial cells rather than of the germinal or follicular cells. This statement is based on the results of transplanting ovaries into spayed animals. It has been noted by numerous investigators that when the ovaries are thus transplanted all the structures except the interstitial cells undergo degenerative changes, yet even when so modified, the transplanted ovary is capable of preventing the typical reactions of ovariotomy. Steinach ('12) demonstrated that the interstitial tissue alone is sufficient to produce feminine traits in the castrated albino rats to which the ovaries were transplanted.

Testes. So far as I am aware, an enlargement of the surviving testis following semi-castration has not yet been reported. 
Failure to observe this response is probably due to the lack of good reference data such as we possess in our laboratory records, and which are necessary to reveal such a change. It has been stated that the testis of the semi-castrated rat shows an increase of 14 to 15 per cent. This increase though small, is highly uniform and occurs in all the series.

I have shown that in the case of the semi-spayed rats the compensatory hypertrophy of the surviving ovary is nearly perfect, and that probably it is the interstitial tissue which increases. Let us see whether the same reaction is possibly occurring in the case of the testes.

Bouin and Ancel ('03 and '04) have brought evidence to show that it is the interstitial cells which are essential for inhibiting the characteristic alterations after castration. They removed one testis in the rabbit and ligated the vas deferens of the other. After ten to twelve months they found a marked hypertrophy of the interstitial eells. They found also that some rabbits, after ligature of the vas deferens, developed characters which follow castration, and they believed that this occurred when nerve as well as the duct was ligated. Vincent and Coleman (cited by Paton '13) found that ligature of the whole spermatic cord, with blood vessels, acts in the same way as castration. On ligating the spermatic cord in rats, I have found the phenomena similar to those reported by Vincent and Coleman. When after this operation the entire testes, including the interstitial cells, degenerate, then the animal manifests the castration reaction. However, if the testes manage to survive partially, though all the germinal cells are degenerated, the rats do not exhibit the castration reaction. From this it seems reasonable to infer that the increase of the remaining testis after the removal of the other must be due to hyperplasia of the interstitial cells. If this inference is correct, the increase of the interstitial tissue though absolutely slight in comparison with the entire testes (for it is only a small fraction of the normal testes), should be relatively large when referred to itself as a standard. Unfortunately we have no data for the rat bearing directly on the normal amount of interstitial tissue in the testes. There are, 
however, some observations on man. Hofmeister ('72) estimates in the human testes at the fourth month the amount of the interstitial tissue to be two-thirds of the whole testes. At eight years of age it constitutes only one-tenth of the organ, but at puberty it again increases somewhat. Taking Hofmeister's estimate of one-tenth of the whole testis for the interstitial tissue as applicable to the adult albino rat, we find the following interesting relations: From table 12 it appears that the average weight of both testes is 2.329 grams for body length of $217 \mathrm{~mm}$. in the control rat, and the weight of the single testis of the semi-castrated is 1.239 grams for a body length of $209 \mathrm{~mm}$. Since the weight of the testes increases with increasing body length, the weight of the testes of the control and of the experimented cannot be directly compared until the difference for the body lengths in the two forms is adjusted. When this correction is made according to the formula (Hatai '13) we find that the one testis of the control is 14 per cent less in weight than the single testis of the semi-castrated. We have assumed that the amount of the interstitial tissue is one tenth of the whole testis, accordingly we find the interstitial tissue to be 0.117 grams for the control and 0.124 grams for the semi-castrated. To this latter value 14 per cent of the weight of the single testis of the control $(=.163)$ must be added to give the assumed value of the interstitial tissue of the semi-castrated. We thus obtain 0.287 grams of interstitial tissue for the single testis of the semi-castrated against 0.117 grams for one testis or 0.233 for both testes of the controls. Thus if we apply the increase of 14 per cent in the entire test is to the interstitial tissue alone, the increase of this latter amounts to over 100 per cent above that of the control. This result depends of course entirely on the correctness of assumption that one-tenth of the whole testes in the albino rats consists of interstitial tissue. Although direct proof of this is lacking, the assumption seems to have some evidence in its favor and none against it. Thus the increase of 14 per cent in the testis as a whole after semi-castration is misleading, for in all probability it really means a doubling in the amount of the interstitial tissue; 
a response almost as complete as that shown by the ovary after semi-spaying.

Skeletal system. Alterations of the bones in weight and in length after gonadectomy have been reported by a number of investigators. Poncet ('97) reported upon rabbits in which he found that castration produces stronger and especially longer bones. Pirsche ('02) found also stronger and longer bones in castrated guinea-pigs. Sellheim ('99) found similar phenomena in the castrated dog. With eunuchs Tandler and Grosz ('13) found constantly longer bones. Without giving any further evidence, it is safe to say that gonadectomy according to these investigators causes an abnormal elongation, and occasionally a thickening of the bones.

In my experiments on albino rats, $\mathrm{E}$ have found that the ratio between body weight and bone weight and the ratio between body length and bone length tend to be slightly higher in the gonadectomized rats than in the controls. The alteration, though constant, is certainly very slight, and indeed the difference between the control and experimented becomes evident only after careful computation. On the other hand, one gets the impression that the skeletal changes reported by other investigators were so large that they could be detected at a glance.

Corresponding data on rats obtained by other investigators are not available for comparison, and thus I am unable to say whether the slight alteration of the bones in weight and length are to be regarded as typical for the albino rat after gonadectomy. However, the water content of the bones was distinctly higher in the gonadectomized rats. At the present moment the interpretation of this phenomenon is not clear. In the semi-castrated rats, there was no alteration either in length, weight or in the amount of water in the bones.

In this connection it may be interesting to note that the tail length of the castrated is noticeably longer than that of the control rat. The difference amounts to 3.2 per cent to 4.7 per cent in the rats which have been operated on at 19 days and 86 days respectively. The rats castrated at 220 days gave a dif- 
ference of 1.8 per cent. On the other hand, the spayed rats do not give this response. To interpret this response will require further experiment, but in the mean time the fact of this occurrence is worthy of note.

\section{Central nervous system}

Gonadectomy is apparently without influence on the central nervous system. The proportional weights of the different parts of the brain and the percentage of water in the several divisions of the system are unmodified, while the slight alterations in the absolute weights of the brain and spinal cord are, by reason of their lack of uniformity, most readily explained as fluctuation. This result is one of prime importance from the standpoint of our general.laboratory problem-the growth of the mammalian nervous system-for it shows that after 15 days of age, gonadectomy, complete or partial, is without influence on the gross structure or fundamental chemical make-up (water and solids) of the nervous system. Further, as the behavior of the female can be induced in the male by the implantation of ovarian tissue (Steinach '12) and the characteristic male behavior ceases after castration, we obtain good evidence for the view already put forward by Steinach that the respective gonads are activators of the nervous system according to sex, and in addition we now have evidence that this is accomplished without recognizable changes in either the structure or the fundamental make-up of the system.

\section{Secondary sexual characters}

Recently Steinach ('10, '12) has made a careful study of these in the albino rat and noted modifications in size of the secondary sex glands, nipples and bones, the changes in hair and in behavior. To the list of modifiable characters which Steinach has given, I am able to make the following additions: The hypophysis of the normal male rat is considerably smaller than that of the female. Castration increases the weight of the hypophysis thus making ti approach that of the female. The suprarenals of the male 
are normally smaller than those of the females. Again castration increases the male suprarenals. At the same time, spaying reduces the suprarenals of the female, thus causing the two sexes to approach each othar in this character. Further, we have found that the tail of the normal male is definitely shorter than that of the normal female. Castration increases the tail length of the male-thus approximating the relation in the female. Again, the body of the adult female is much smaller both in length and weight than that of the adult male. Spaying induces an overgrowth of the female body both in length and in weight, while castration tends to make the male body somewhat less than normal, thus bringing the two sexes nearer together. Speaking very generally, we might say that gonadectomy tends to produce the secondary characters found in the opposite sex.

\section{SUMMARY}

All the experiments were made on albino rats. There were five series, representing five different operations:

1. Total gonadectomy: castration and spaying.

2. Partial gonadectomy: semi-castration and semi-spaying.

3. Ligation of spermatic cord.

4. Removal of one ovary, followed by an isolation of the other ovary from the uterus.

5. The isolation of both ovaries from the uterus.

The following body characters and organs (or some of them) were measured in each series: Body length, body weight, tail length, sex glands, thyroid, suprarenals, thymus, hypophysis, various long bones and the central nervous system. The main results are given under the characters studied.

(1) Body length. Comparing the operated animals with the controls, the absolute body lengths were found to be slightly less in all the operated rats except the spayed females in which the body lengths were distinctly greater.

(2) Tail length. The tail with respect to the body length tends to be slightly longer in the castrated males, but no significant alterations occur in the other series. 
(8) Body weight. The body weight in respect to body length is greater in nearly all operated rats, but especially is this the case in the spayed rats.

(4) Weight and length of the bones. These characters are not modified in the semi-spayed rat, but in the castrated as well as in spayed rats, the bones (femur, tibia and fibula; humerus, radius and ulna) tend to be very slightly longer and heavier than in the corresponding controls. The bones were not ex amined in the other series. The percentage of water in the bones is also slightly higher in the operated than in the controls. No alteration was noted in the semi-spayed in this respect.

(5) Central nervous system. No characteristic response can be reported for the central nervous system. The differences in total weight after gonadectomy appear to be fluctuations merely. The different parts of the brain were not modified in their relative weights, and the water content of the brain and of the spinal cord were the same in both the operated and in the controls.

(6) Sex glands. In the semi-spayed series the compensatory growth of the remaining ovary is almost perfect as it attains nearly twice its normal size. In the case of the semi-castrated series the remaining testis shows an increase of 14 per cent as a whole. If however we assume that the increase is due solely to hyperplasia of the interstitial tissue, and further, if we take Hofmeister's estimate of the interstitial tissue as one tenth of the entire testes in the human testes and apply it to the rat, we obtain compensatory growth in the interstitial tissue in the semicastrated rat which is almost as great as in the case of the remaining ovary of the semi-spayed rat. The isolated ovaries survived and grew as if these had been connected with the uterus. In the case of isolation of the ovary followed by semispaying, the remaining isolated ovary hypertrophies in the same manner as that of the semi-spayed rat. The ligation of the spermatic cord in certain cases causes a complete atrophy of the testes, thus producing the alterations of the body characters similar to those which appear in the castrated rats. 
(7) Thyroid gland. On account of its great variability in weight, no definite conclusions can be drawn from the variations observed in the weight of the thyroid gland.

(8) Suprarenal glands. The suprarenal glands show opposite reactions in the two sexes as the result of gonadectomy. In the castrates, the suprarenals show an increase, and in the spayed rats, a decrease. No adequate explanation can be given for this singular phenomenon. The suprarenal glands fail to give any response in all the other experiments, except those where the spermatic cords were ligated. In these last the suprarenals show reactions similar to those which follow castration in group II where the testes has been absorbed.

(9) Thymus. The thymus gland shows a very striking response to gonadectomy, though no noticeable alterations were found to follow partial gonadectomy. After the former operation the thymus increases to almost twice the size which it has in the control rats. The thymus seems not only to delay its normal involutionary process but actually to increase in weight as the result of gonadectomy. Gonadectomy enables the thymus of the old rat to respond, and thus a highly atrophied thymus may become enlarged almost as much as if the operation were performed on young animals.

(10) Hypophysis. Following the removal of the testes, the weight of the hypophysis is increased on the average as much as 50 per cent. On the other hand, spaying produced only a slight increase (about 8 per cent on the average). This difference in reaction according to sex has been noted in my previous experiments (1912 series). All the other series show an almost insignificant variation, except the ligation of the spermatic cord which, when followed by absorption of the testis, gives a response similar to castration.

(11) Relations of the hypophysis to the growth of gonadectomized rats. After removal of the sex glands, it appears that when compensatory growth of the hypophysis occurs, there is no overgrowth of the body or obesity. On the other hand, both these latter responses appear when the enlargement does not occur-as 
in the spayed rats, for example. In the semi-spayed, as well as in the semi-castrated, neither enlargement of the hypophysis nor overgrowth and obesity occur, because the enlargement of the remaining ovary or testis enables the surviving sex gland to furnish the normal amount of gonadine.

(12) Secondary sexual characters. The total removal of the sex-glands tends to increase the resemblance between the two sexes, or, in other words, to reduce the differences in those secondary characters which, in the normal animal, are marks of sex. Put in another way, we may say with equal truth that gonadectomy in a given sex tends to produce the secondary characters found in the opposite sex.

\section{LITERATURE CITED}

Barnabo, V. 1908 Sui rapporti tra la glandola interstiziale del testicolo e le glandole a secrezione interna. Il Policlinico, tom. 15.

Bond, C. J. 1906 Some points in uterine and ovarian physiology and pathology in rabbits. British Med. Jour., vol. 2.

1906 The by-effects of hysterectomy and "oöphorectomy. British Med. Jour., vol. 2.

Bikd, A. 1913 Innere Sekretion. 2nd edition. Urban and Schwarzenberg. Berlin.

Bours, P., and ANCEL, P. 1903 Recherches sur les cellules interstitielles du testicule des mammifères. Arch. de Zool. Exper., tom. 1, 4th series. 1904 Recherches sur la signification phys. de la glande interstitielle du testicule des mammifères. Journ. de phys. et de path. gen., vol 6.

Calzolari, A. 1898 Recherches experim. sur un rapport probable entre la fonction du thymus et celle de testicule. Arch. ital. de biol., tom. 30 .

Carmichael, E. S., and Marshall, F. H. A. 1908 On the occurrence of compensatory hypertrophy in the ovary. Jour. of Physiol., vol. 36.

Crmoroni, A. 1907 Sull'ipertrophia dell'ipofisi cerebrale negli animali stiroidati. Lo Sperimentale, tom. 61, and Arch. Ital. de Biol., tom. 48.

Cushing, H. 1909 The hypophysis cerebri. Clinical aspect of hyperpituitarism and of hypopituitarism. Jour. Amer. Med. Assoc., vol. 53.

Donaldson, H. H., and HATAI, S. 1911 Note on the influence of castration on the weight of the brain and spinal cord in the albino rat and on the percentage of water in them. Jour. Comp. Neur., vol. 21.

Engelhors, E. 1912 Schilddrüse und weibliche Geschlechtsorgane. Sitz. der phys.-med. Sozietät in Erlangen, Bd. 43.

Feodossiew, N. E. 1906 Hypertrophie der Nebennieren nach Entfernung der Eierstöcke. Russkij Wratch, vol. 5. 
Fichers, G. 1905 Sur l'hypertrophie de la glande pituitaire consécutive à la castration. Arch. Ital. de Biol., tom. 43.

1910 Recherches expérimentales sur les processus de réparation et de compensation a la suite d'une intervention sur l'ovarie. Arch. Ital. de Biol., tom. 53.

Gellin, O. 1910 Die Thymus nach Extirpation, bzw. Röntgenbestrahlung der Geschlechtsdrüsen. Zeitschr. f. exper. Path. u. Ther., Bd. 8, no. 1.

Goodall, A. 1904 The postnatal changes in the thymus of guinea pigs and the effect of castration on thymus structure. Jour. Physiol., vol. 32.

Hammar, J. A. 1905 tber Thymusgewicht und Thymuspersistenz beim Menschen. Verhandlungen der Anat. Gesellschaft.

HataI, S. 1913 On the weights of the abdominal and thoracic viscera, the sex glands and the eyeballs of the albino rat (Mus norvegicus albinus) according to body weight. Am. Jour. Anat., vol. 15.

1913 a The effect of castration, spaying or semi-spaying on the weight of the central nervous system and of the hypophysis of the albino rat; also on the remaining ovary. Jour. Exp. Zool., vol. 15.

1914 On the weight of the thymus gland of the albino rat (Mus norvegicus albinus) according to age. Am. Jour. Anat., vol. 16.

Henderson, J. 1904 On the relationship of the thymus to the sexual organs. Jour. of Physiol., vol. 31.

Hofmeister, F. 1872 Untersuchungen über die Zwischensubstanz im Hoden der Säugetiere. Sitz. der math.-naturwiss. Klasse der K. K. Akad. der Wissenschaften, Wien. Bd. 65, abt. 3.

JACKson, C. M. 1913 Postnatal growth and variability of the body and of the various organs of the albino rat. Am. Jour. Anat., vol. 15.

KLose, H., and VoGr, H. 1910 Klinik und Biologie der Thymusdrüse mit besonderer Berücksichtung ihrer Beziehungen zu Knochen und Nervensystem. Beitr. klin. Chir., Bd. 69.

Kolmer, W. 1912 Beziehungen von Nebennieren und Geschlechtsfunktion. Archiv für die ges. Physiol., Bd. 144.

KoN, J. 1909 Hypophysenstudien. 2. Uber das Verhalten der Hypophyse nach Kastration. Ziegler's Beiträge zur path. Anat. und zur allg. Path., Bd. 64.

Livingston, A. E. 1914 Effect of castration on the weight of the pituitary in rabbits. Proc. Soc. Exper. Biol. and Med., vol. 11, no. 2.

Marrassini, A. 1910 Sur les modifications que la castration peut déterminer dans les organes glandulaires de quelques animaux, et spécialement sur celles que l'on recontre dans l'hypophyse. Arch. Ital. de Biol., tom. 53.

Marrassini, A., and Luciani, L. 1911 Effets de la castration sur l'hypophyse et sur d'autres glandulaires. Arch. Ital. Biol., tom. 56.

Marshall, F. H. A. 1910 The physiology of reproduction. Longmans \& Co., London.

Parbon, C., and Goldatein, M. 1905 Sur l'existence d'un antagonisme entre les fonctions de l'ovaire et celle du corps thyroïd. Arch. général de med., tom. 82. 
PAton, D. N. 1904 The relationship of the thymus to the sexual organs. Jour. Physiol., vol. 32.

1913 The nervous and chemical regulators of metabolism. McMillan \& Co., London.

Prrsche, E. 1902 De l'influence de la castration sur le dévelopement du squelette. Thèse de Lyon.

Poncet, 1878 Influence de la castration sur le développement du squelette. Assoc. Franc. pour l'avanc. d. Sc. C. r. Paris.

Schenk, F. 1910 Utber die Veränderungen der Nebennieren nach Kastration. Beitr. z. klin. Chir., Bd. 67.

Sellewerm, H. 1898 Zur Lehre von den sekundären Geschlechtscharakteren. Beitr. z. Geb. u. Gynäk., Bd. 1.

1899 Kastration und Knochenwachstum. Ibid., Bd. 2.

1901 Kastration und sekundäre Geschlechtscharaktere. Ibid., Bd. 5.

Shattock, C. G., and Seligmann, C. G. 1904 Observation upon the acquirement of secondary sexual characters indicating the formation of an internal secrotion by the testicle. Proc. Roy. Soc., vol. 73, London,

Sour, U. 1907 Comment se comportent les testicules chez les animaux privés de thymus. Arch. Ital. de Biol., tom. 47.

1909 Contribution a Ia connaissance de la fonction du thymus chez le poulet et chez quelques mammiferes. Arch. Ital. de Biol., tom. 52 . 1909 a Modifications du developpement des os chez les animaux privés de thymus. Arch. Ital. de Biol., tom. 52.

Steinach, E. 1910 Geschlechtstrieb und echte sekundäre Geschlechtsmerkmale als Folge der innere sekretorischen Funktion der Keimdrüsen. Zentralbl. f. Physiol., Bd. 24.

1912 Willkürliche Umwandlung von Säugetiermännchen in Tiere mit ausgeprägt weiblichen Geschlechtscharakıeren und weiblicher Psyche. Archiv für die ges. Physiol., Bd. 25.

Stilling, H. 1898 Fur Anatomie der Nebenniere. Arch. f. Mikrosk. Anat., Bd. 52.

StotsenbdrG, J. M. 1913 The effect of spaying and semi-spaying young albino rats (Mus norvegicus albinus) on the growth in body weight and body length. Anat. Rec., vol. 7, no. 6.

TANdLer, J. 1910 Uber den Einfluss der innersekretorisehen Anteile der Geschlechtdrüsen auf die ässuere Erscheinung des Menschen. Wiener klin. Wochenschr. Jahrg. 23.

TandLer, J., and Grosz, S. 1907 Einfluss der Kastration auf den Organismus. Wien. klin. Wochenschr. Jahrg 20.

1913 Die biologischen Grundlagen der sekundären Geschlechtscharaktere. Julius Springer, Berlin.

VinCEnT, S. 1912 Internal secretion and ductless glands. Edward Arnold, London. 


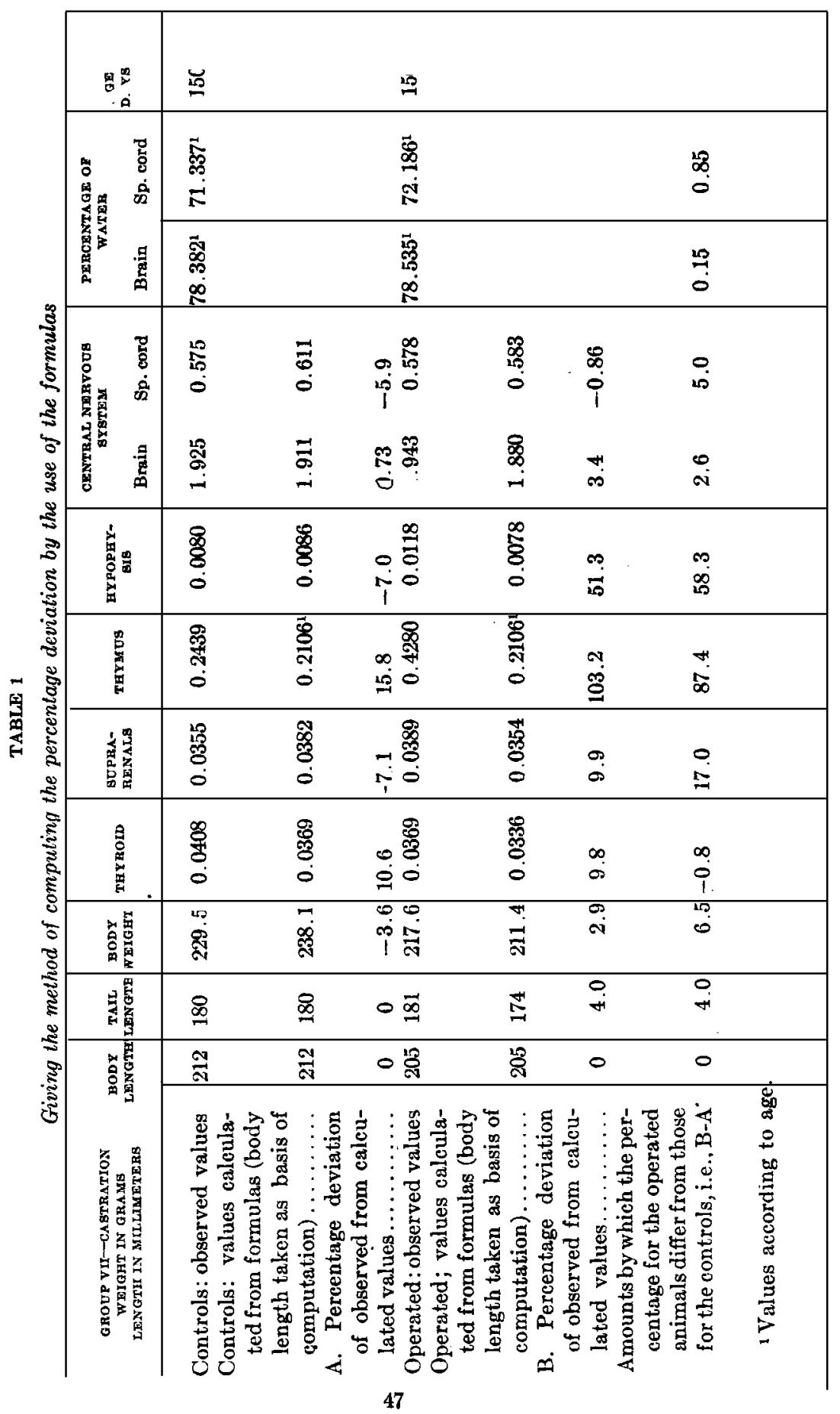




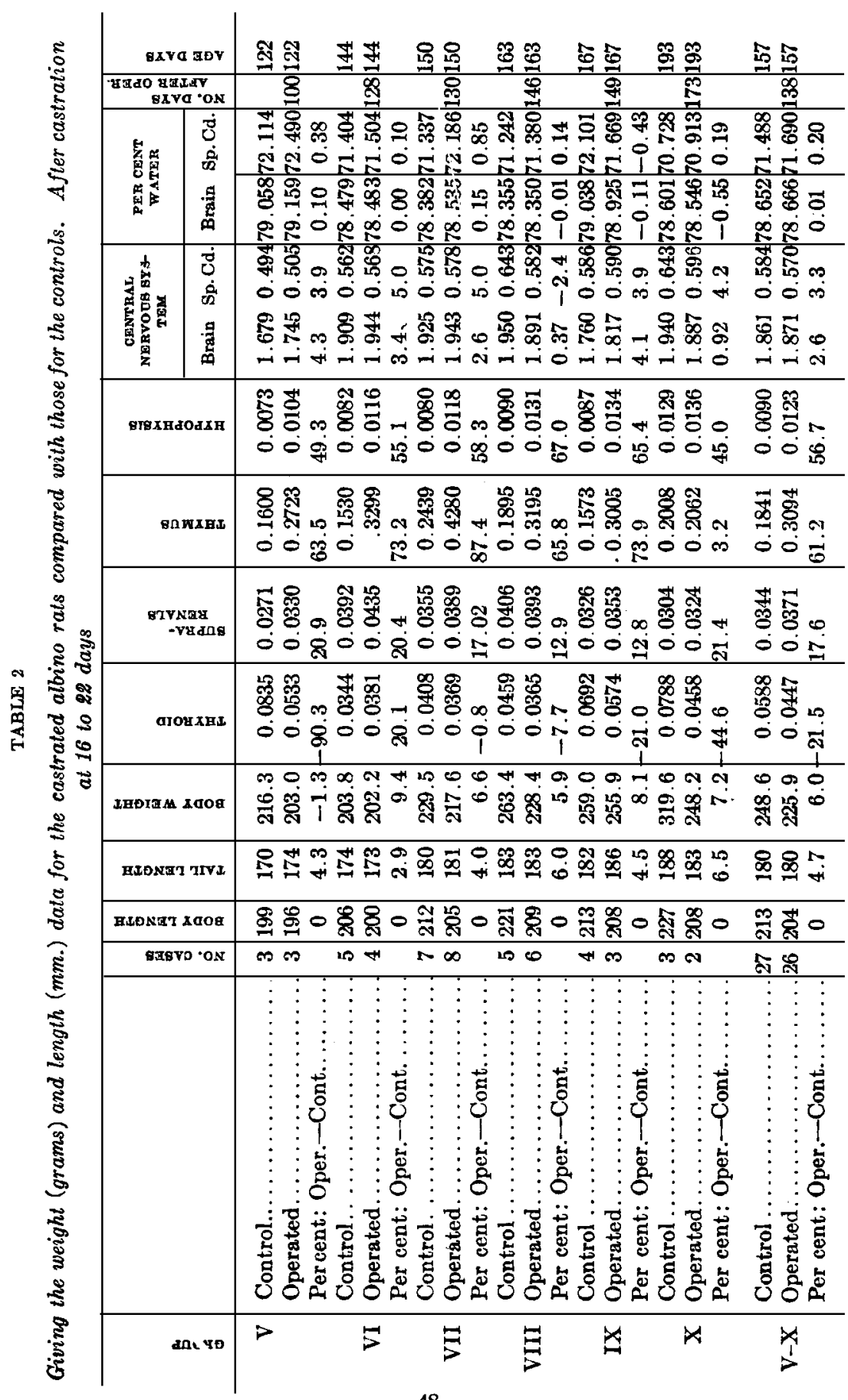




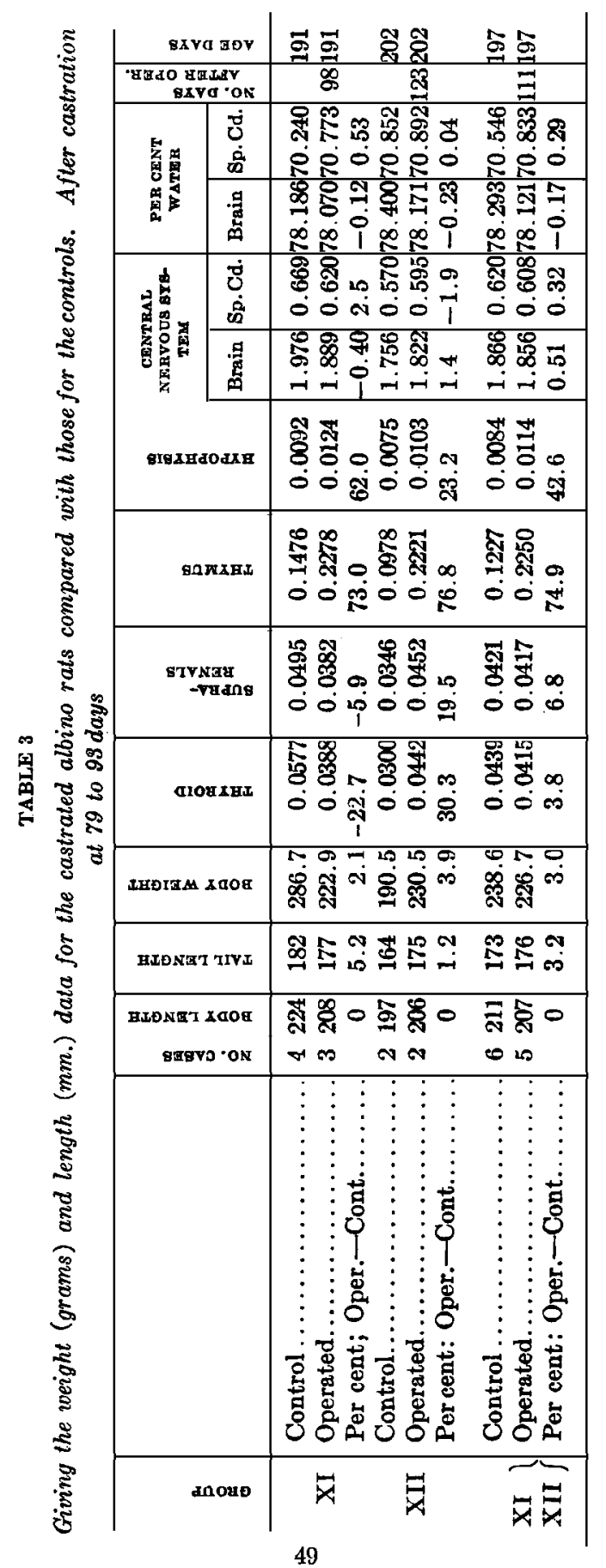

THE IOURNAL OF EXPERMENTAL ZOOLOQY, YOL. 18, NO. 1 


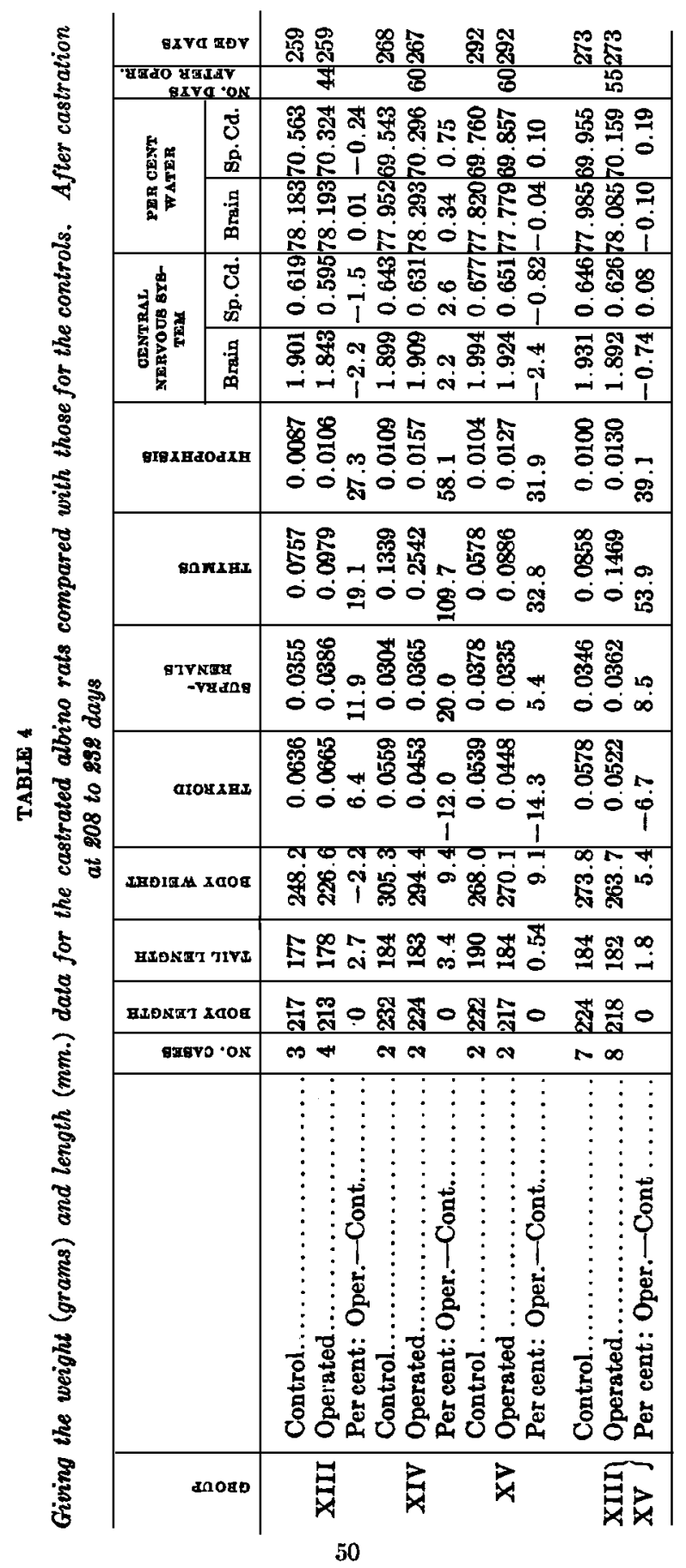




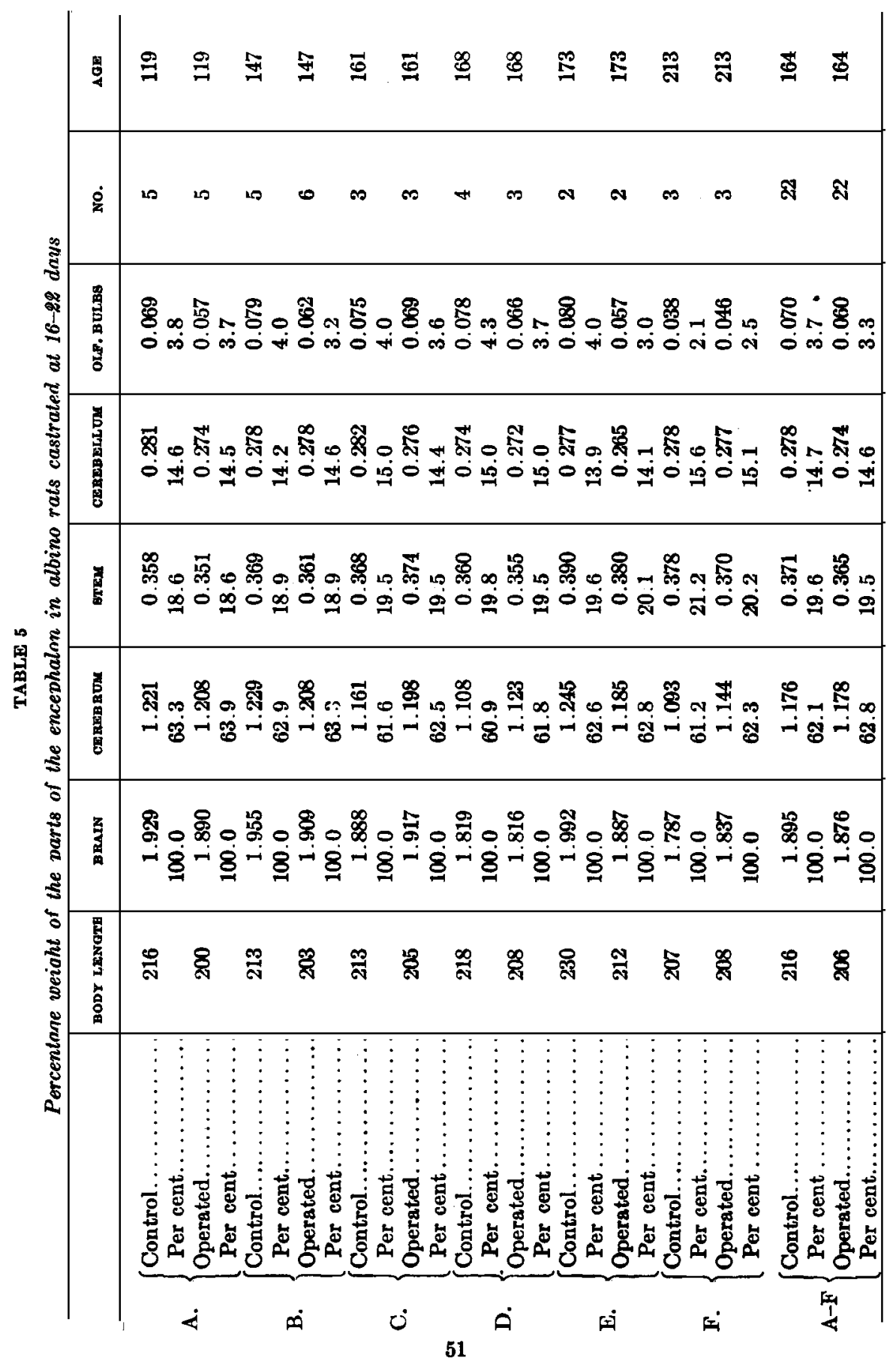




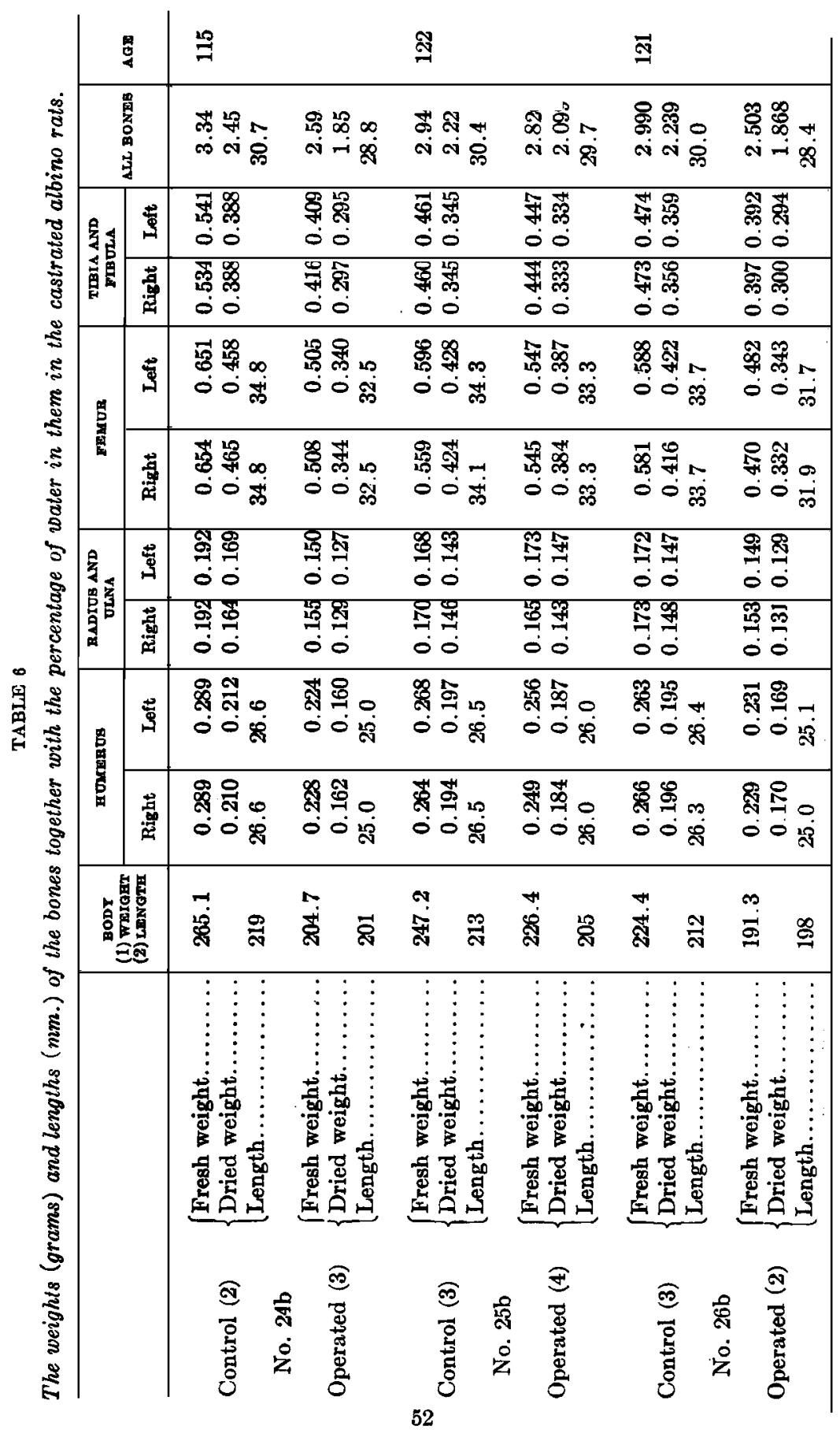




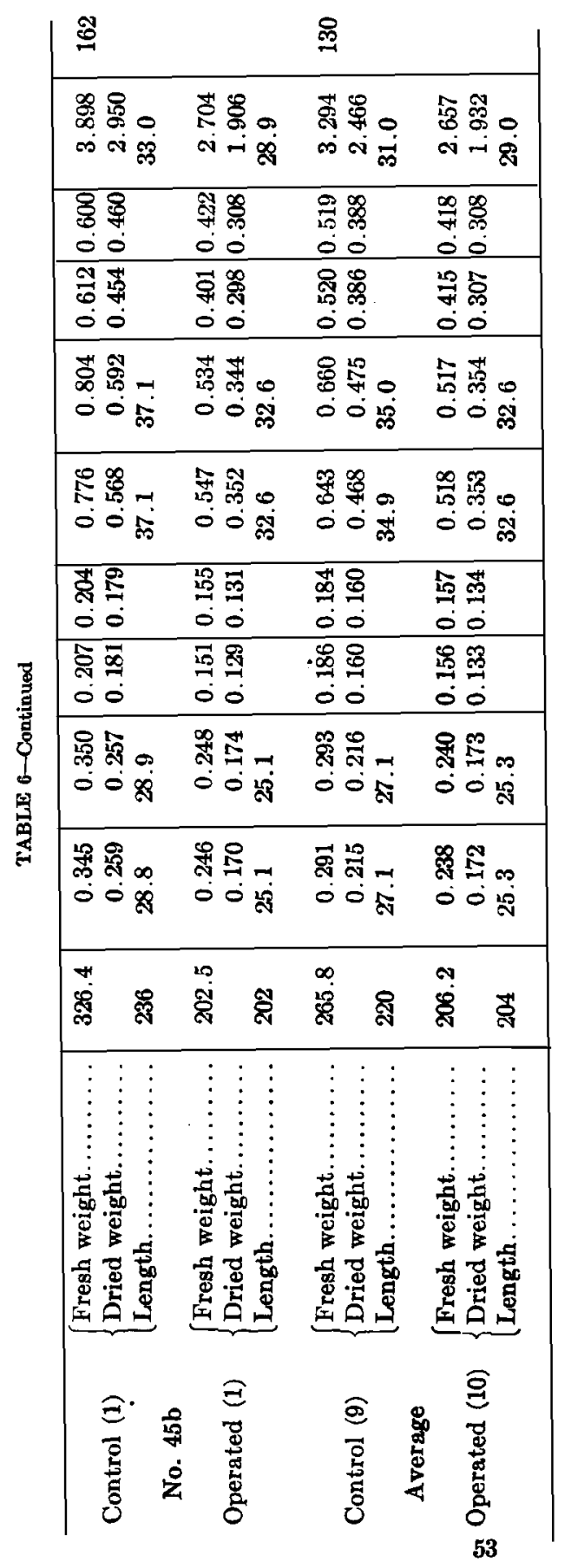




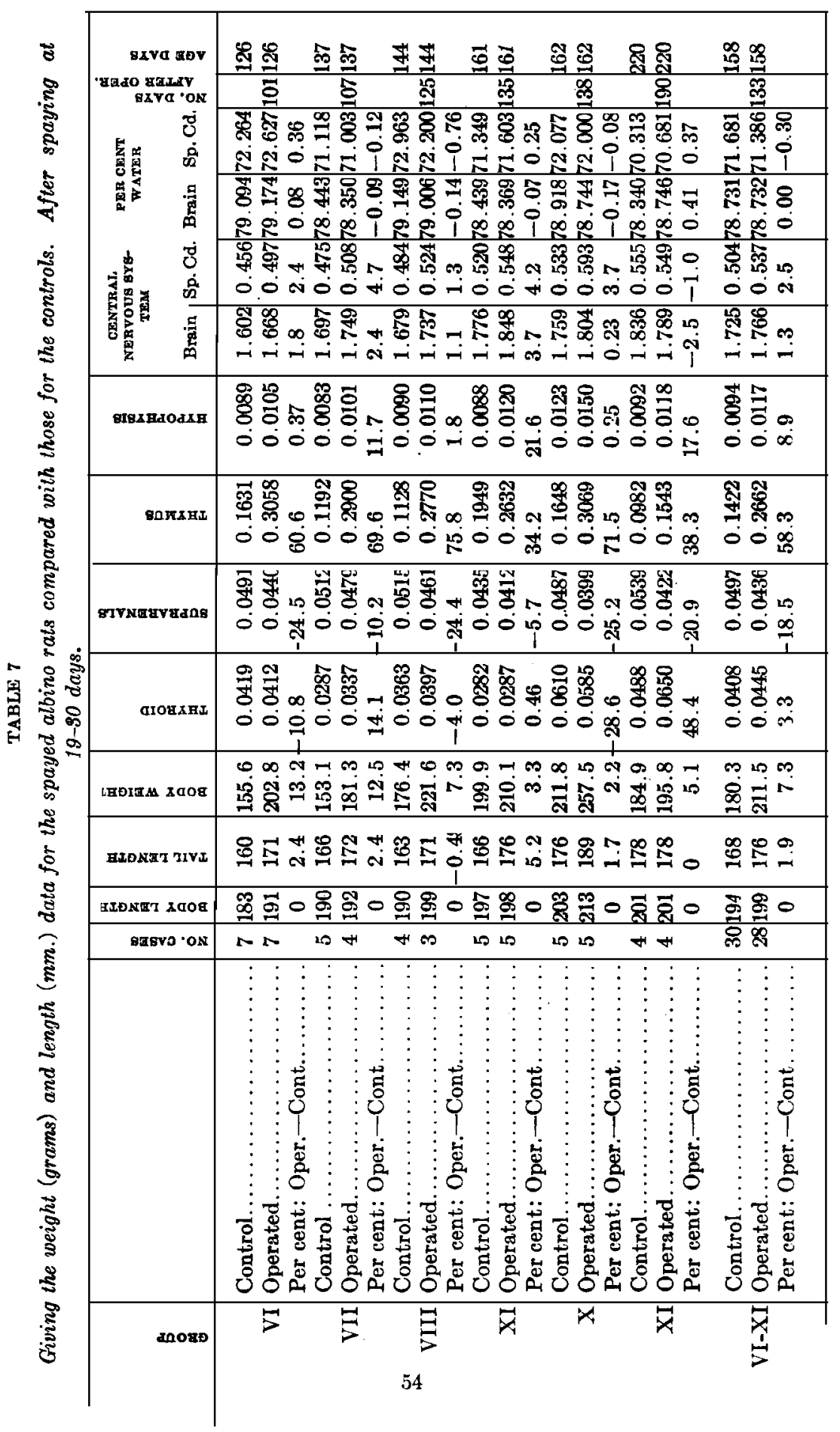




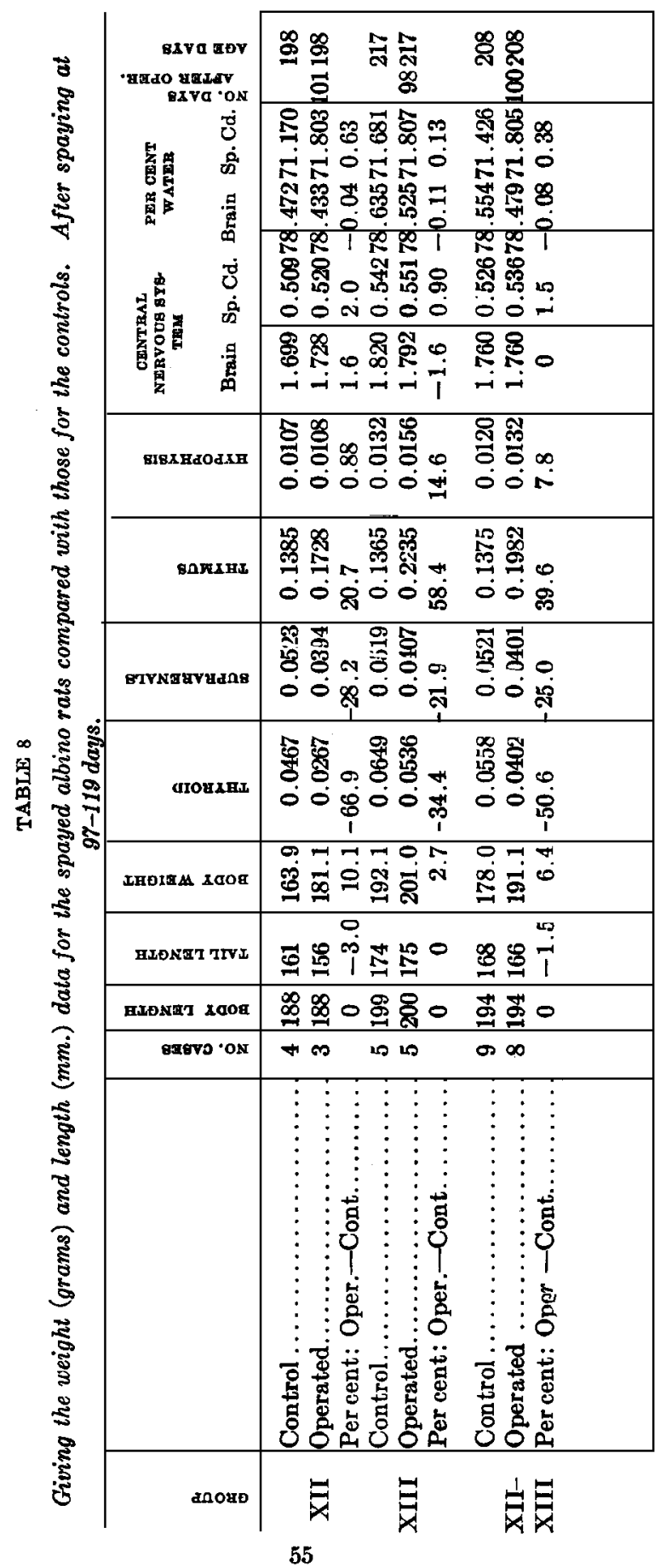




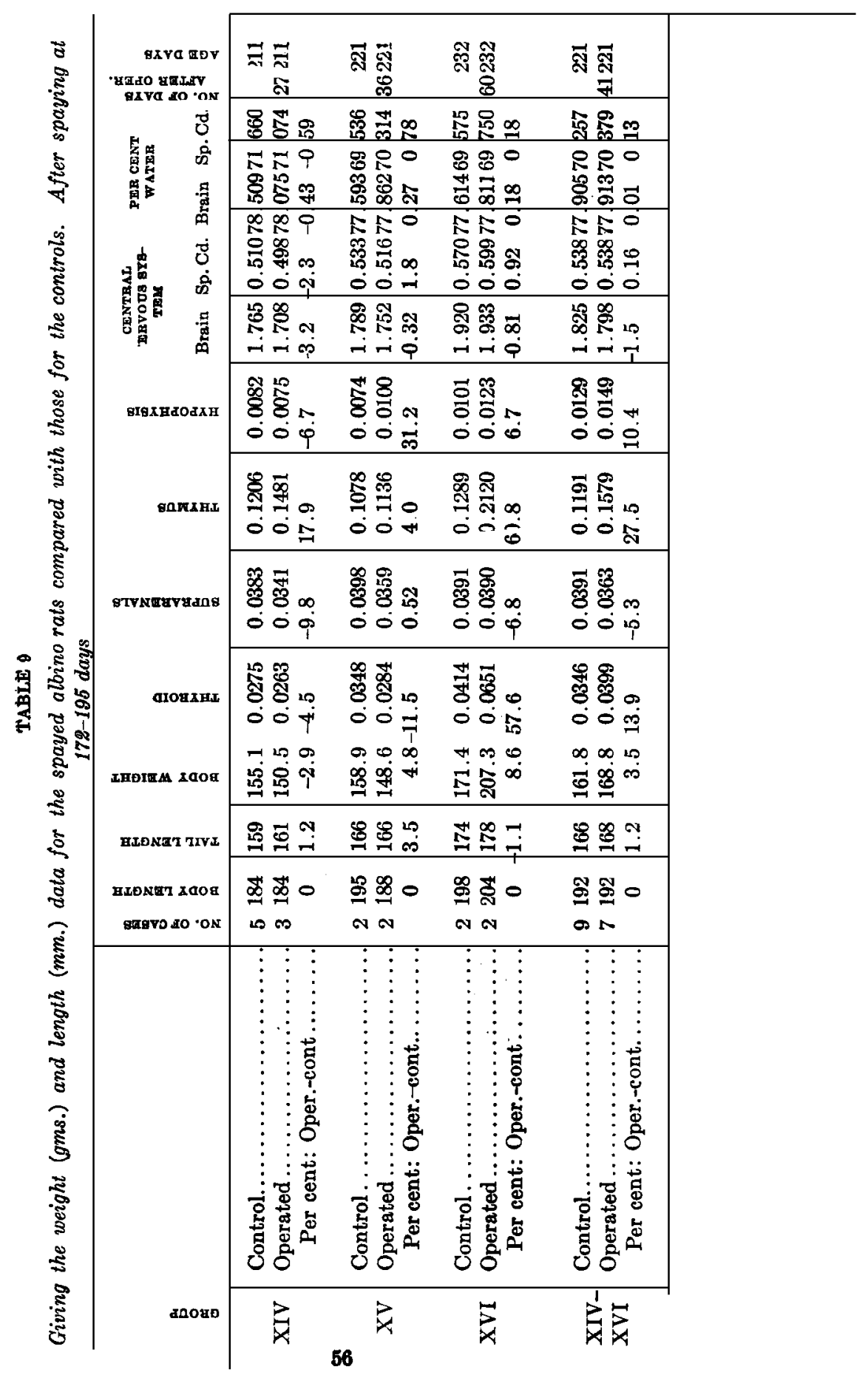




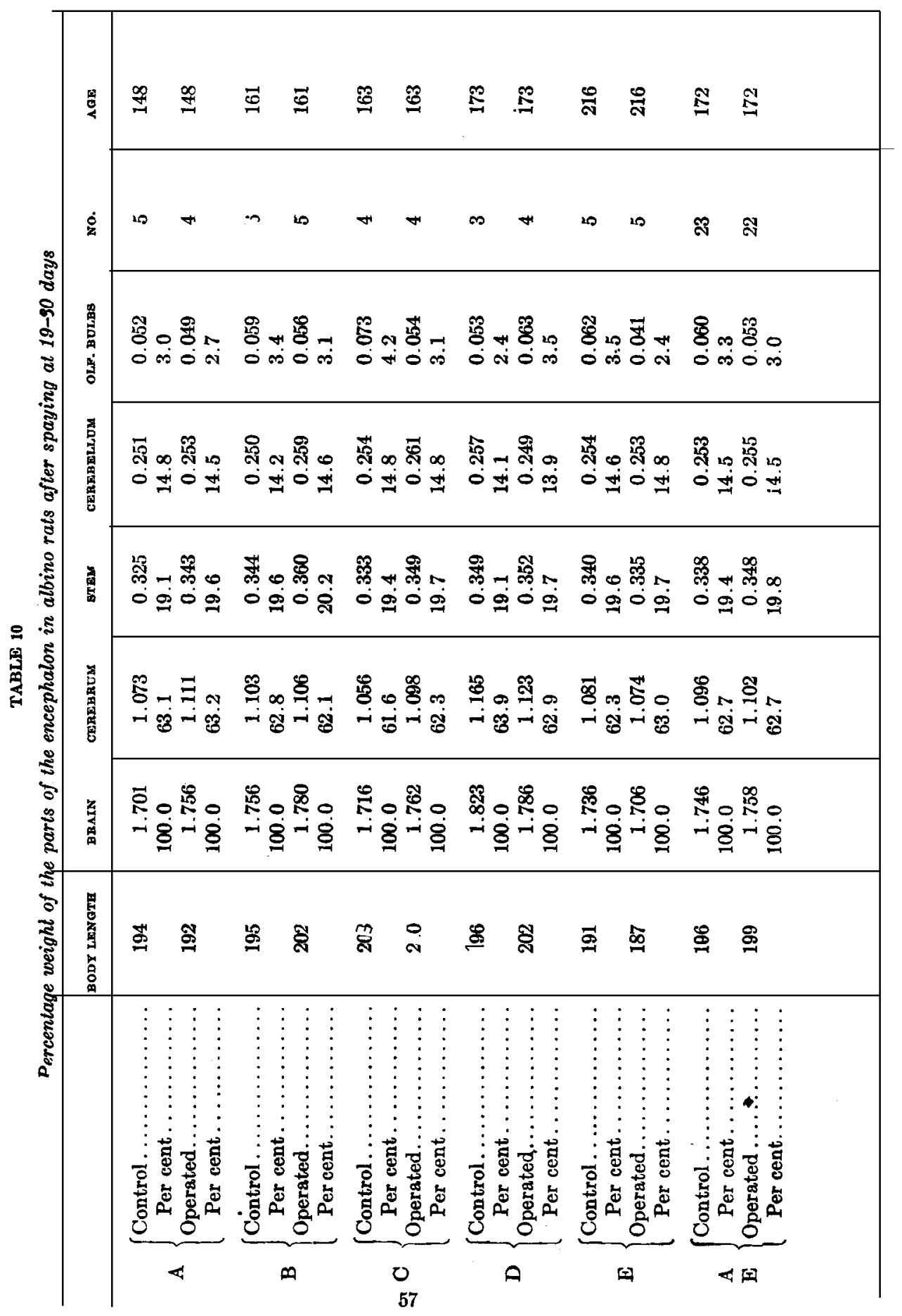




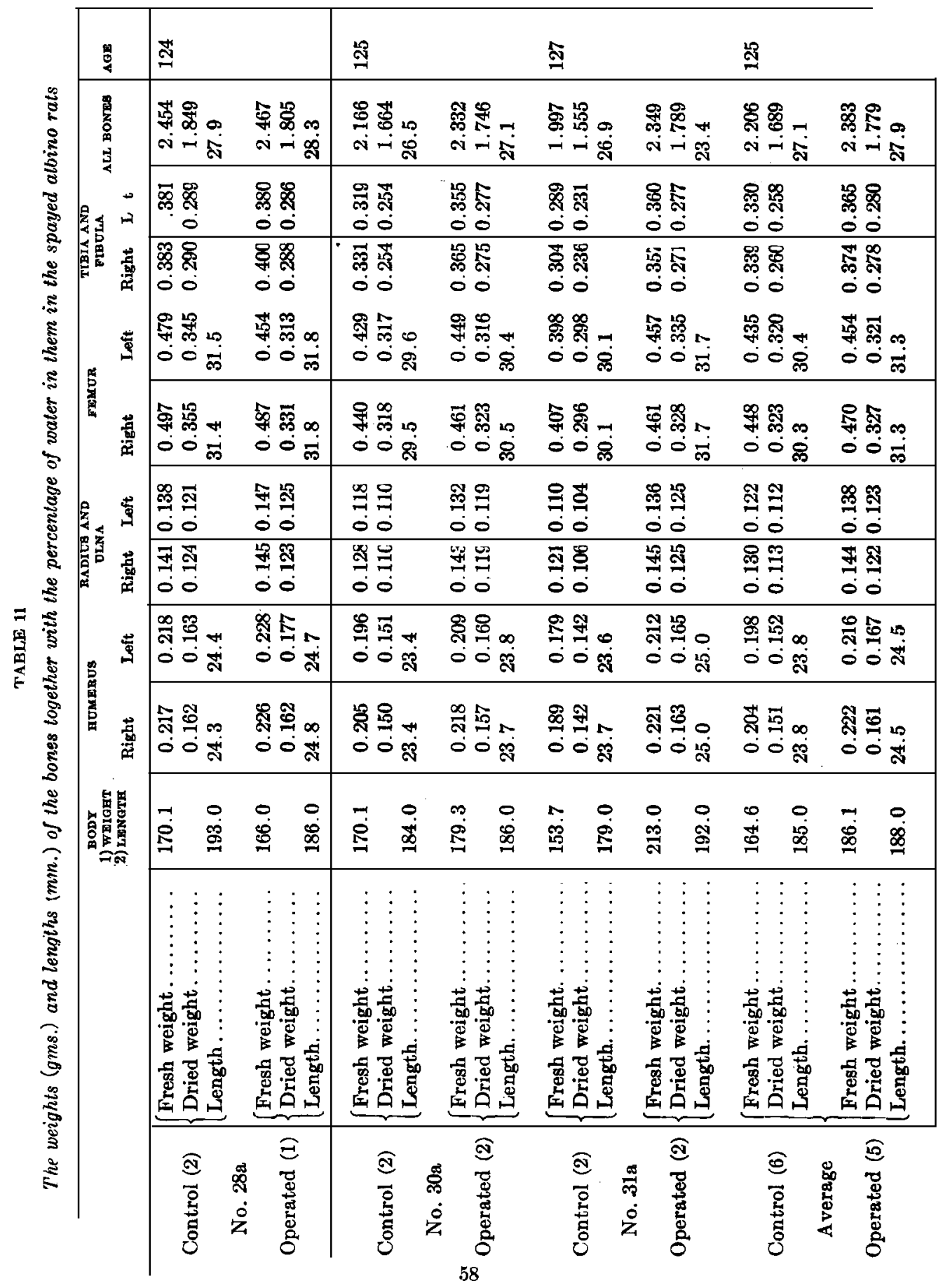




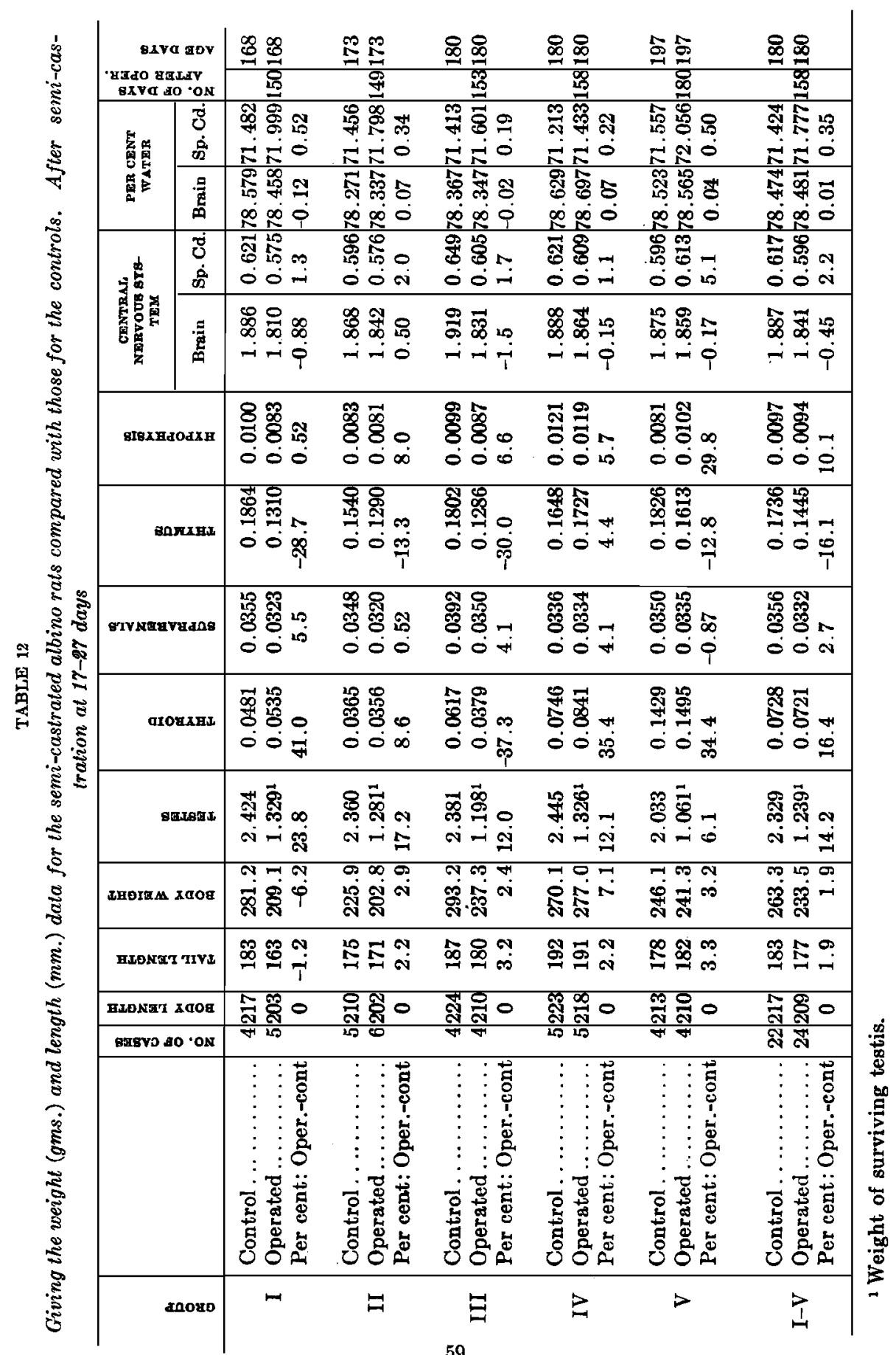




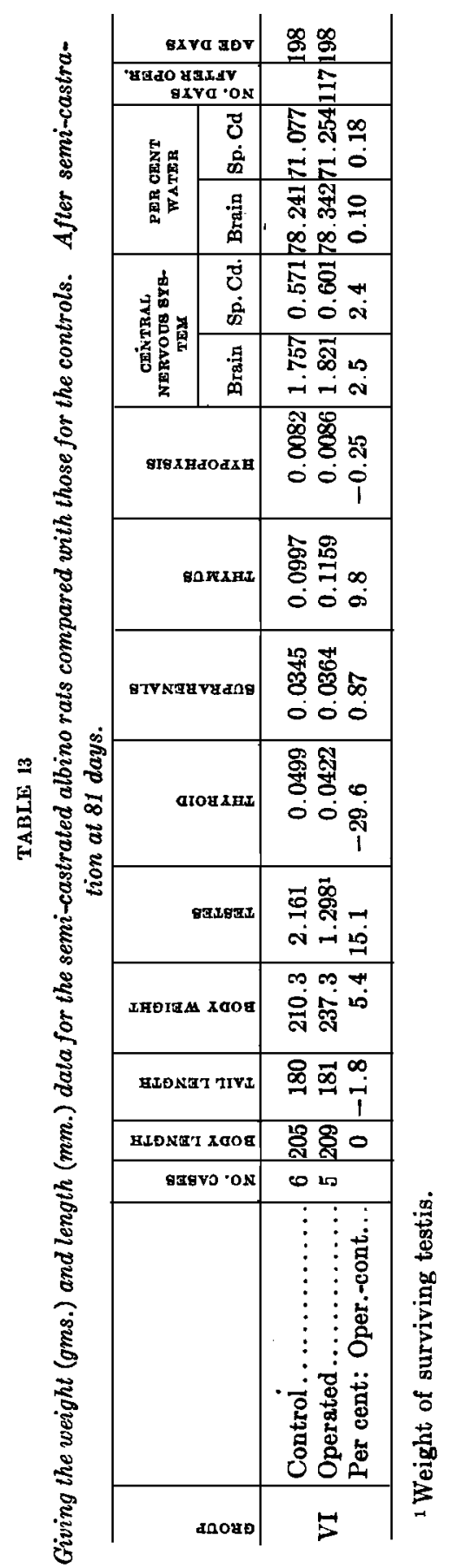

60 


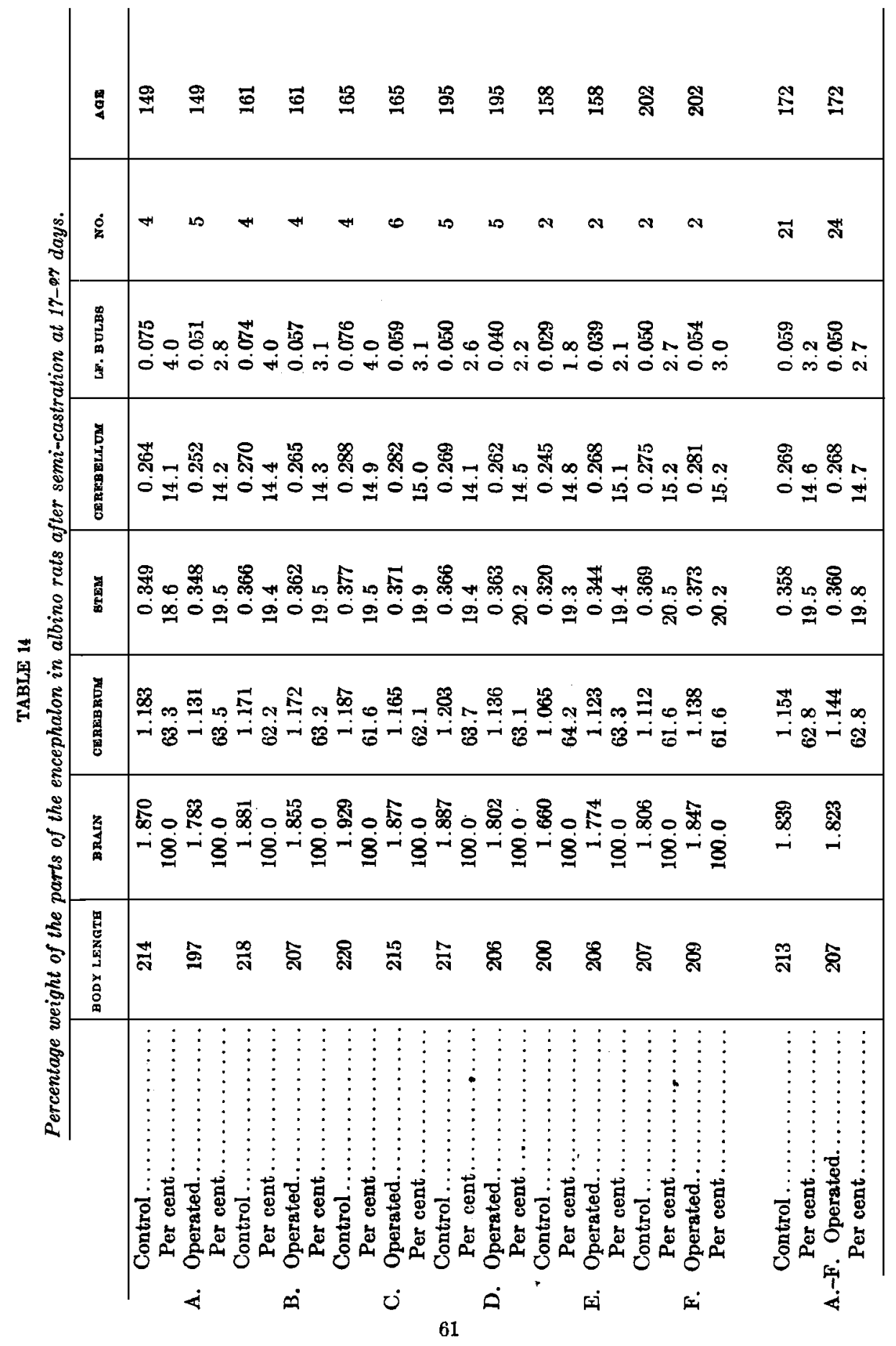




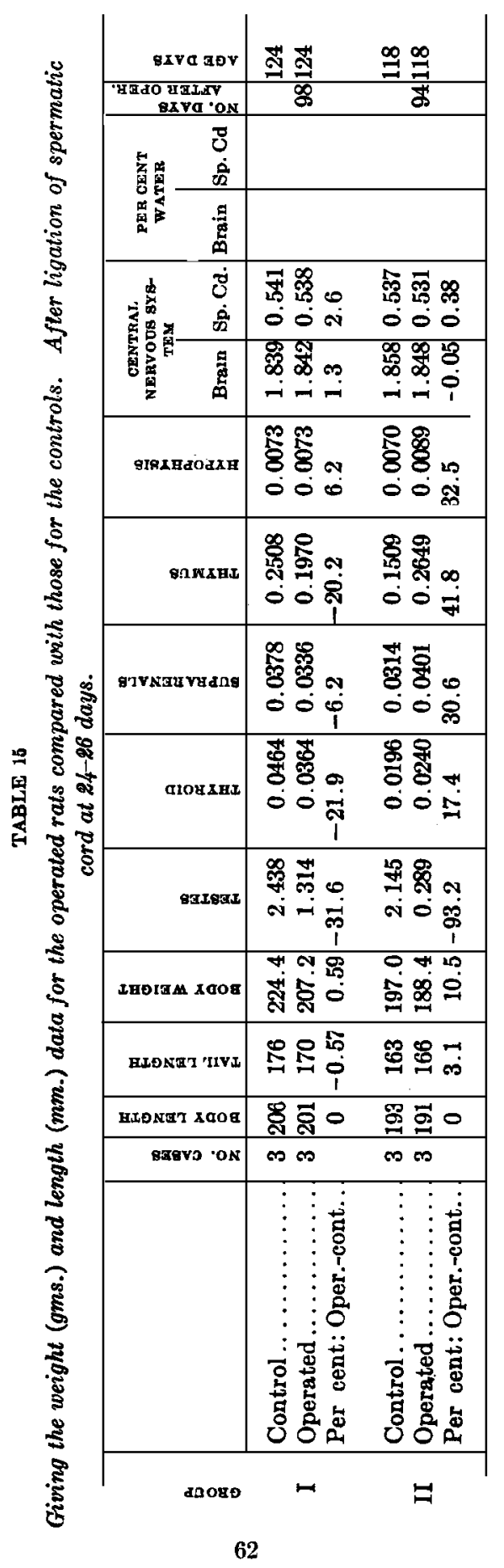




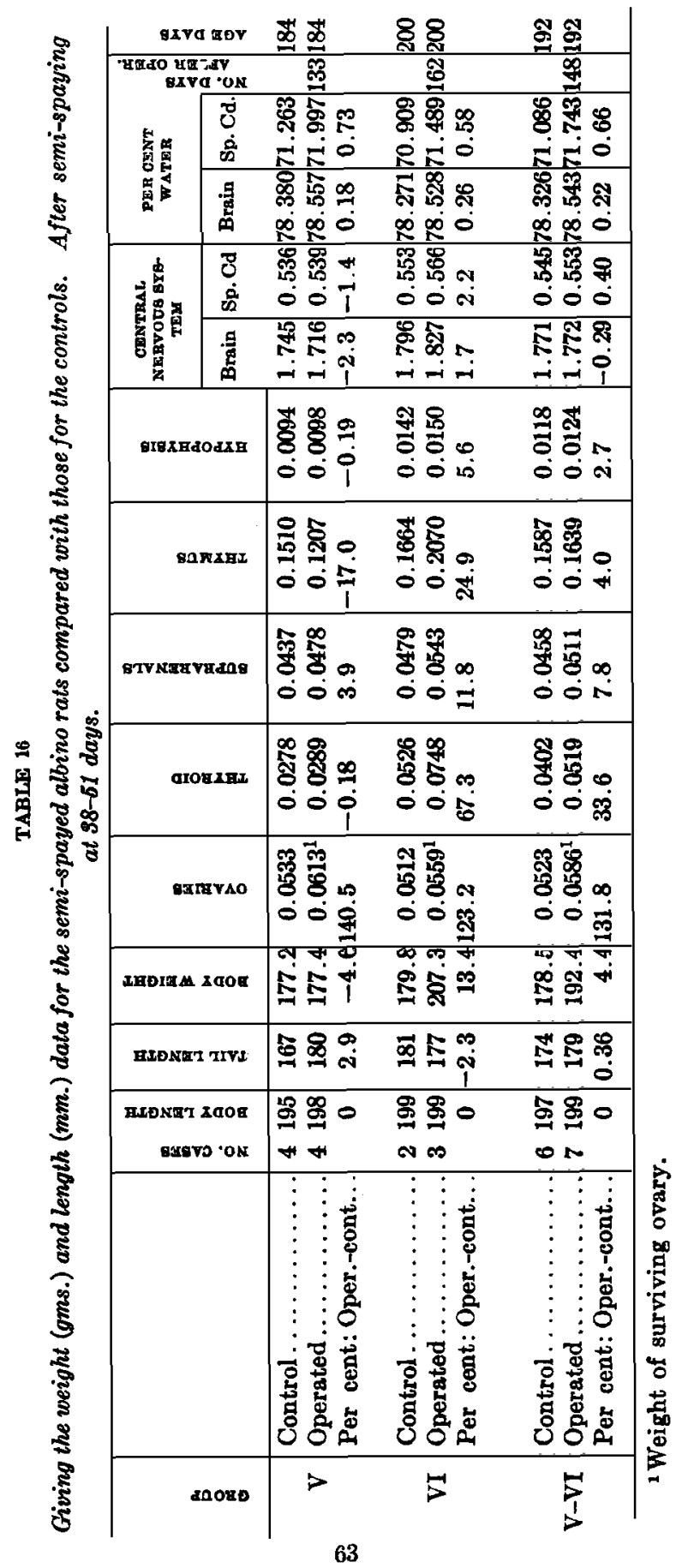




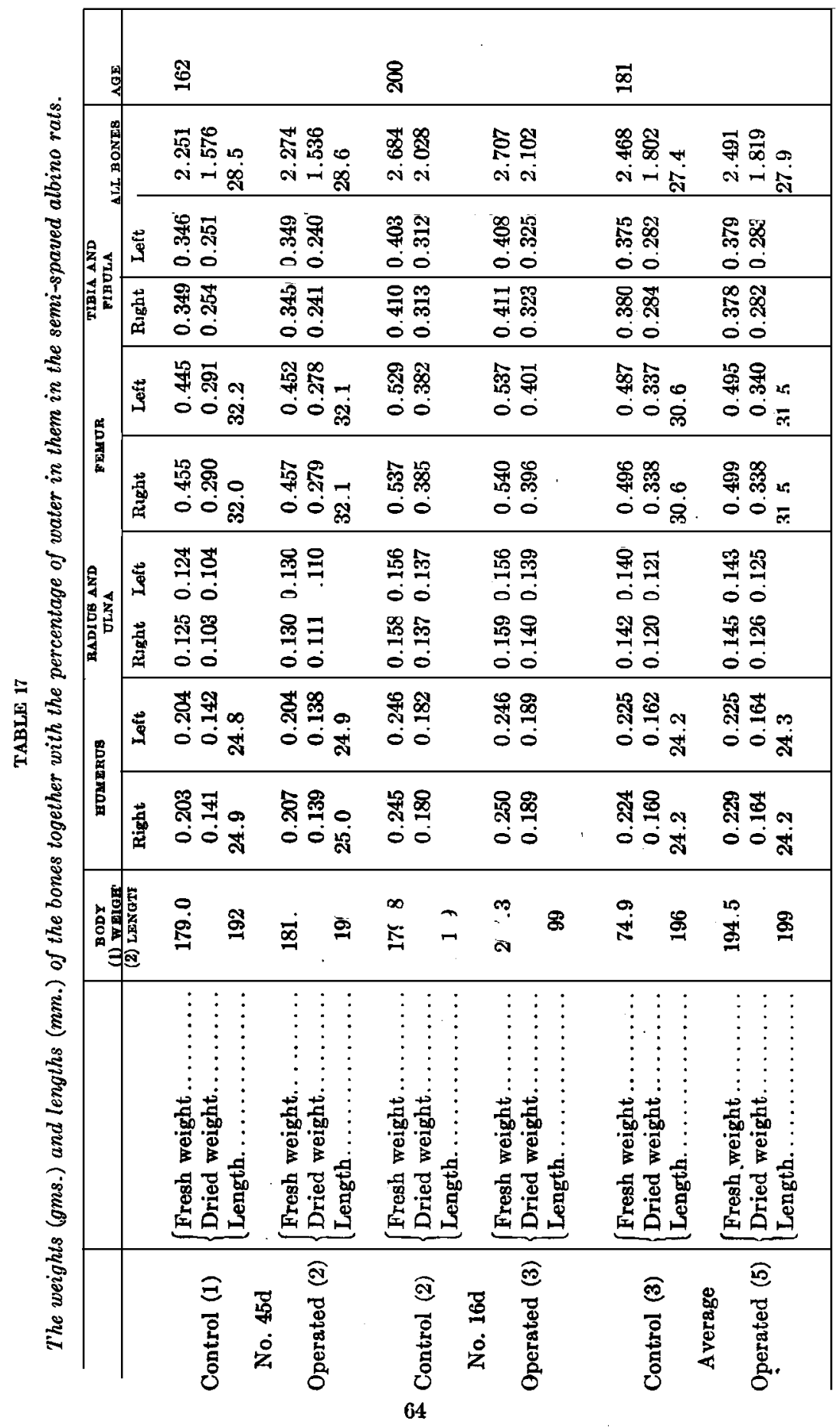




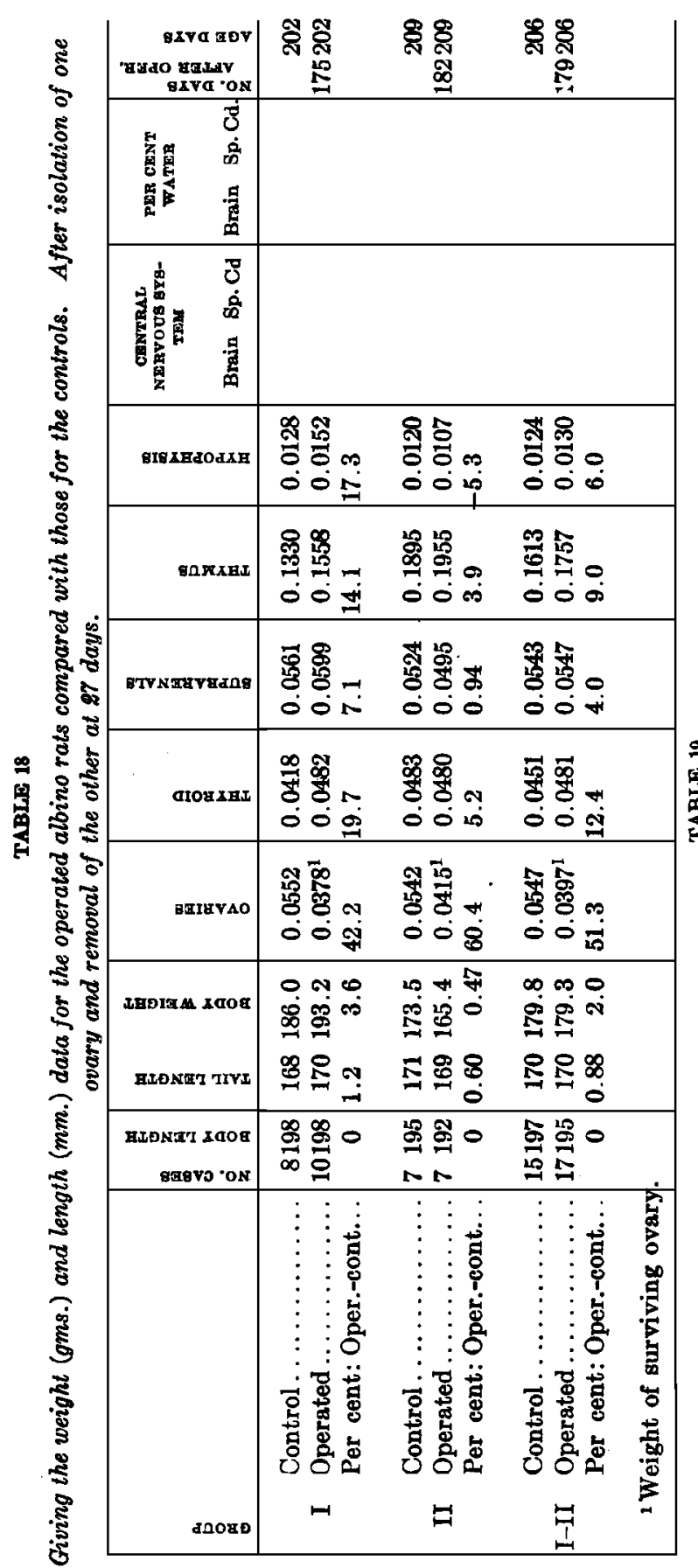

65

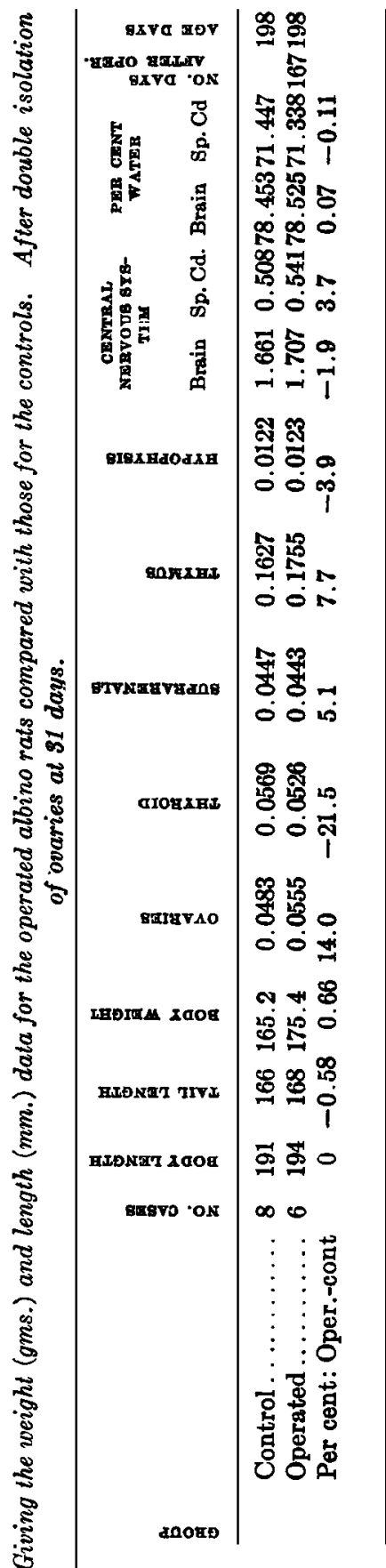

THE JOURNAL OF EXPERIMENTAL ZOÖLOGY, VOL. 18, No. 1 


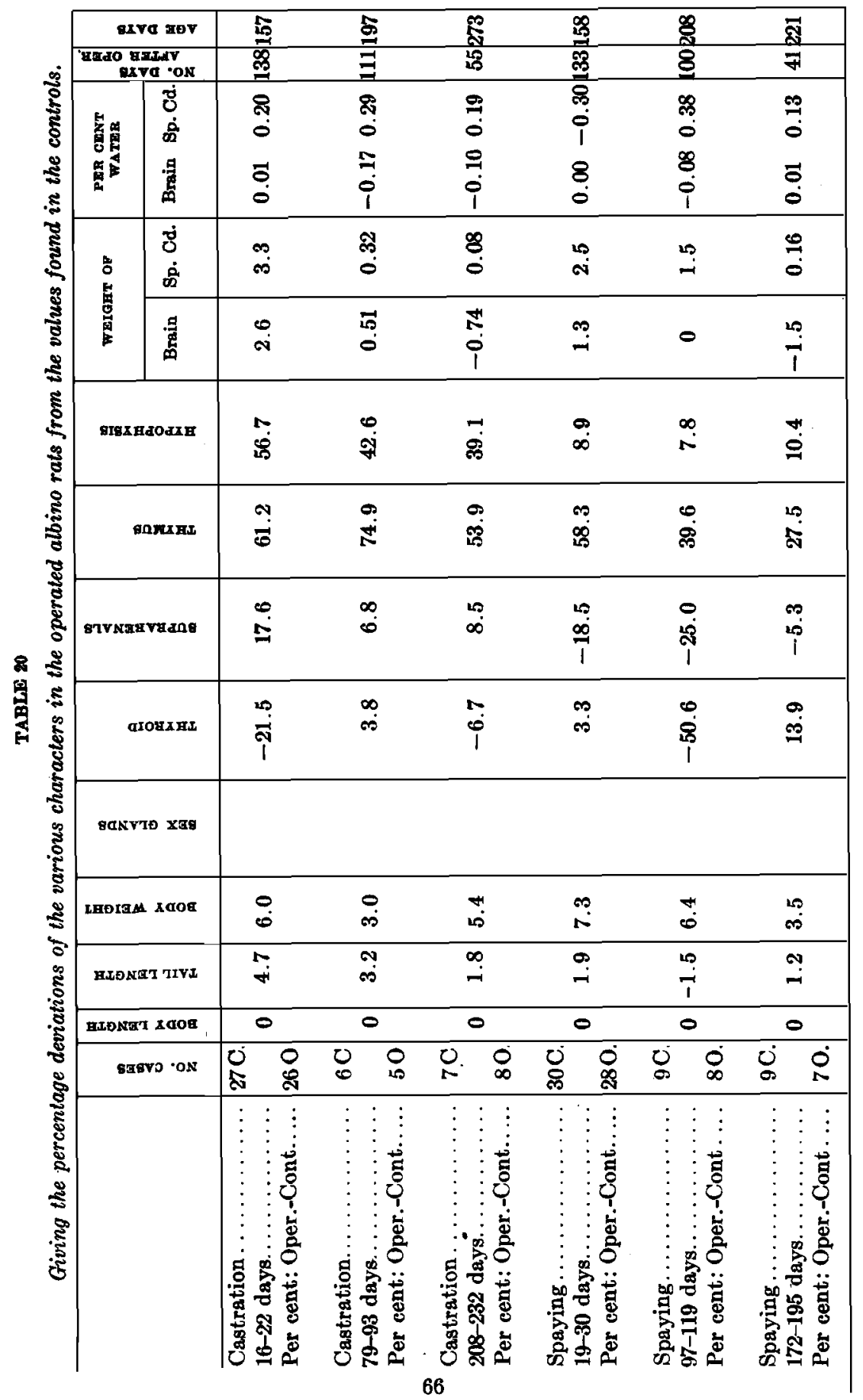




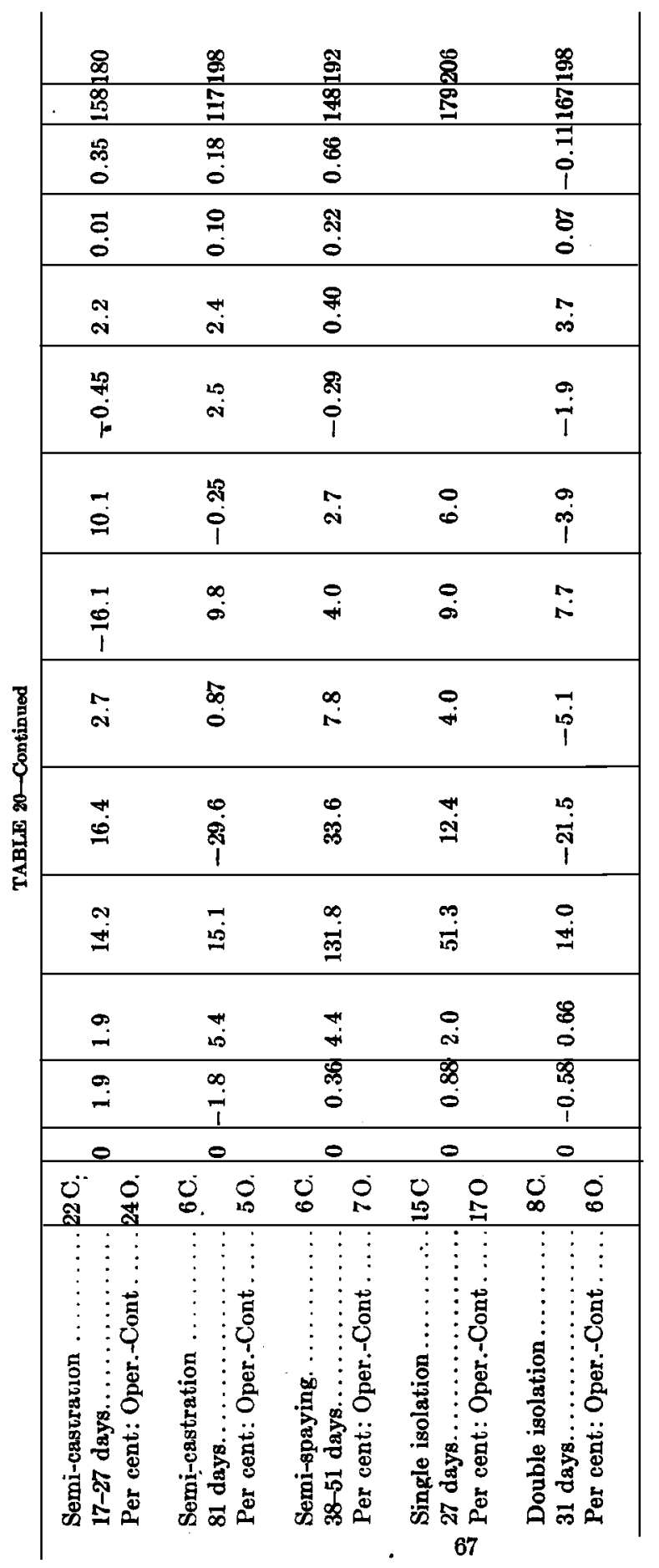

